University of Texas Rio Grande Valley

ScholarWorks @ UTRGV

Civil Engineering Faculty Publications and

Presentations

6-3-2021

\title{
Modeling Triaxial Testing with Flexible Membrane to Investigate Effects of Particle Size on Strength and Strain Properties of Cohesionless Soil
}

\author{
Thang Pham \\ The University of Texas Rio Grande Valley, thang.pham@utrgv.edu \\ Md. Wasif Zaman \\ The University of Texas Rio Grande Valley \\ Thuy $\mathrm{Vu}$ \\ The University of Texas Rio Grande Valley
}

Follow this and additional works at: https://scholarworks.utrgv.edu/ce_fac

Part of the Civil Engineering Commons

\section{Recommended Citation}

Pham, T., Zaman, M.W. \& Vu, T. Modeling Triaxial Testing with Flexible Membrane to Investigate Effects of Particle Size on Strength and Strain Properties of Cohesionless Soil. Transp. Infrastruct. Geotech. (2021). https://doi.org/10.1007/s40515-021-00167-6

This Article is brought to you for free and open access by the College of Engineering and Computer Science at ScholarWorks @ UTRGV. It has been accepted for inclusion in Civil Engineering Faculty Publications and Presentations by an authorized administrator of ScholarWorks @ UTRGV. For more information, please contact justin.white@utrgv.edu,william.flores01@utrgv.edu. 


\title{
Modeling Triaxial Testing with Flexible Membrane to Investigate Effects of Particle Size on Strength and Strain Properties of Cohesionless Soil
}

\author{
Thang Pham ${ }^{1}$, Md. Wasif Zaman², Thuy $\mathrm{Vu}^{3}$ \\ ${ }^{1}$ Assistant Professor, Department of Civil Engineering, University of Texas Rio Grande Valley, \\ Edinburg, TX, USA. thang.pham@utrgv.edu \\ ${ }^{2}$ Graduate Assistant, Department of Civil Engineering, University of Texas Rio Grande Valley, \\ Edinburg, TX, USA. mdwasif.zaman01@utrgv.edu \\ ${ }^{3}$ Associate Professor, Department of Civil Engineering, University of Texas Rio Grande \\ Valley, Edinburg, TX, USA. thuy.vu@utrgv.edu
}

\begin{abstract}
A 3D DEM model using Particle Flow Code ( $\mathrm{PFC}^{3 \mathrm{D}}$ ) software was developed utilizing a bonded-ball flexible membrane approach to study cohesionless soil as a discontinuous discrete material. This approach is not yet widely used because of its complexity and high computational cost, but it allowed the authors to observe the stress-strain curves of triaxial specimens, to single out effects of individual factors on the strength and strain properties, and to observe the formation of the shear band and failure surface. The 3D model was calibrated and verified with experimental data, and a sensitivity analysis was carried out for the microparameters. Triaxial tests were simulated to observe the stress-strain curves and volumetric changes, as well as the strength parameters of soils consisting of spherical particles with different gradations but the same porosity. The authors investigated the effects of mean particle size, larger particle size, smaller particle size, and soil gradation on three soil parameters: peak deviatoric stress, internal friction angle, and dilatancy angle. Four different cases with different soil gradations and particle sizes were studied: a uniform soil, a soil with randomly created particle sizes, and two soils each contains two particle sizes. For two out of the four cases studied, peak deviatoric stress, internal friction angle, and dilatancy angle increased when the mean particle size $D_{50}$ increased. For the other two cases, the parameters decreased when the mean particle size $D_{50}$ increased. One important finding is that the relationships between particle size and deviatoric stress, internal friction angle, and dilatancy angle were found to be linear. These relationships can provide predictions on soil strength and strain properties when the particle size changes. Observations and discussions on the formation of shear bands during shear testing are also presented. A step-by-step delineation of the DEM model development is also presented with the development process of a flexible membrane carefully described.
\end{abstract}

Keywords: Triaxial test simulation, grain size, cohesionless soil, flexible membrane, numerical analysis, DEM.

\section{Introduction}

The strength and strain properties of cohesionless soil which is a granular, discontinuous, and heterogeneous material, are of importance and are usually determined using laboratory tests. Laboratory testing, such as the axisymmetric drained triaxial test, is time-consuming and may require the involvement of highly skilled personnel with expensive instruments. Numerical modeling is another approach to obtaining the cohesionless soil's stress-strain relationship, 
strength, and volume change. Numerical methods such as the finite element method (FEM) and discrete element method (DEM) have been used for decades to simulate geotechnical laboratory tests to investigate the constitutive laws that apply to this type of soil [1-7]. For modeling granular materials, FEM, which utilizes continuum mechanical analyses, has some major disadvantages. FEM does not account for the geometry and behavior of a particle as an isolated entity [3]. Moreover, FEM is not capable of modeling physical phenomena such as anisotropy, micro-fractures, and localized instabilities [7]. Kishino (1988) stated that the determination of a constitutive model for FEM modeling is significantly difficult [2]. With FEM, a constitutive model based on the continuum approach usually requires some material input or model parameters that sometimes do not have a clear physical meaning. Also, FEM cannot solve the model if the displacement between elements is relatively large since it is formulated by small strain theory. DEM, on the other hand, has better modeling capabilities to capture the mechanical behavior of granular material better than FEM does [4,6]. DEM has also proven to be a reliable approach to delineating the distinct elements that dictate the constitutive behavior of granular materials [6]. DEM can define different particle shapes and sizes: spherical, flaky, elongated, or irregular, small or large. For these advantages, DEM was employed in this study for the analyses of strength and strain properties of cohesionless soil by modeling triaxial testing.

Behaviors of a triaxial test specimen can be significantly affected by the type of confining membrane, especially in terms of reaching peak strength and dilation [8-11]. Membrane properties significantly affect the movement of particles at the outer edge of a specimen under the application of loads. Vermeer (1990) revealed that the formed shear bands during shear failure are highly dependent on membrane flexibility, i.e., "flexible" or "rigid" [12]. For lab testing, researchers have successfully implemented flexible boundaries to plane strain compression tests [11,13-16]. The traditional rigid boundary model in DEM analyses has drawbacks compared to the flexible membrane boundary because: (1) a rigid cylindrical wall cannot enable local strain displacement during triaxial shearing, and (2) non-uniform stress distributions exist along the boundary wall due to the forced alignment of particles located near the rigid wall [17]. Simulated triaxial models with a rigid wall boundary underestimate the deviator stress in the post-elastic zone $[18,19]$. With the rigid wall, the actual failure surface and the volume change cannot be determined. The DEM flexible membrane model best reflects the real working condition of a triaxial test, but the modeling approach is complicated and computationally expensive. Nevertheless, because of its advantages, the flexible modeling approach was adopted for this study.

The effects of particle size on the behavior of discontinuous granular materials have generated much research for many years [20-23] with both experiments and modeling. As Ben et al. (2010) and Cundall and Hart (1993) stated, the effects of particle size must be identified to obtain accurate predictions of the behavioral characteristics of granular soil[24,4]. However, studies on the effects of particle size have been somewhat inconsistent and contradictory. Kirkpatric (1965) and Marschi et al. (1972) concluded from experimental studies that the friction angle decreases with increasing uniform particle size [25,26]. Xiaofeng et al. (2013) investigated the effect of coarse-grained content on the stress-strain response of gravel soil and concluded that shear strength increases with the increase of coarse gravel content in the specimen [27]. Kim and Ha, (2014) performed large direct shear tests and concluded that a larger particle size results in higher shear strength [28]. However, Sitharam and Nimbkar (2000) with DEM triaxial test simulations observed no significant changes in shear strength and volume change due to particle size for parallel gradations; shear strength decreases to a considerable extent for a wider gradation which results in a decrease in the angle of internal friction [29]. Bagherzadeh-Khalkhali and Mirghasemi (2009) using a DEM model to simulate 
direct shear test reported that internal friction angle and dilation increase due to particle size is more significant by scalping gradation than parallel gradation [30]. Mishra and Mahmud (2017) performed DEM direct shear test simulations to study particle size effects on two commonly used ballast gradations for railroad tracks, Arema \#4 and Arema \#24 [31]. Significant changes in internal friction angle due to particle size were observed for Arema \#4 ballast material; however, no consistent trend was found for gradually changing gradation for Arema \#24. Islam et al. (2011) performed a series of direct shear tests considering uniform particles and graded particles, and observed that with the increase of particle size, angle of internal friction angle increases for both uniform sands and graded sands [32].

One important condition that must be met when performing experiments or simulations on the effects of particle size is to make sure that the initial void ratio/porosity remains the same for the different gradations. Some research pertaining to particle size effects on shear strength parameters was not reliable because this condition was not met [33,29]. A reason for the contradictory results is that it is difficult to single out one factor from others, and on occasion, the models did not correctly reflect the working condition of the soil, especially when using a fixed boundary for triaxial DEM models.

Based on the preceding records of inconsistencies, this paper addresses the need for further study on the effects of particle size on the strength and strain properties of granular soil. To close this information gap, this paper presents DEM simulations on triaxial tests with flexible membranes used to investigate the impacts of particle size on the stress-strain behaviors and strength and strain properties of soil. The developed DEM model, verified with experimental data, can create soil specimens with the same porosity, and can single out individual factors that affect soil strength and strain properties. This research is also an important first step toward modeling the stress-strain behaviors of reinforced soil in a mechanically stabilized earth (MSE) retaining wall or in a geosynthetic reinforced soil (GRS) mass.

\section{Background}

For a laboratory triaxial test, a flexible rubber or latex membrane is usually used to cover the specimen for the application of hydrostatic confining pressure. With this flexible boundary, triaxial shearing causes substantial bulging which in turn results in the formation of the shear failure bands. When simulating the laboratory test using DEM, if the rigid boundary was used, the specimen was created within that rigid boundary, which means the bulging condition could not be observed. Movement of the rigid wall was controlled by a servomechanism to maintain a constant confining pressure $\left(\sigma_{3}\right)$, and the shear band at the end of simulation could not be observed. These issues were addressed by using a flexible membrane; however, modeling a flexible membrane is complicated and computationally expensive. Figure 1 shows a triaxial test before and after triaxial shearing with the typical bulging shape. Using flexible membrane modeling, the failure surfaces and shear bands can be viewed clearly. Qu et al. (2019) mentioned two major difficulties in modeling latex/rubber membranes during triaxial testing by DEM: (1) the precise application of hydrostatic confining pressure while simultaneously (2) ensuring the free deformation of the membrane boundary [34]. This problem has led to the creation of different methods for modeling a flexible membrane in DEM by researchers wanting to better understand the behaviors of soil. 


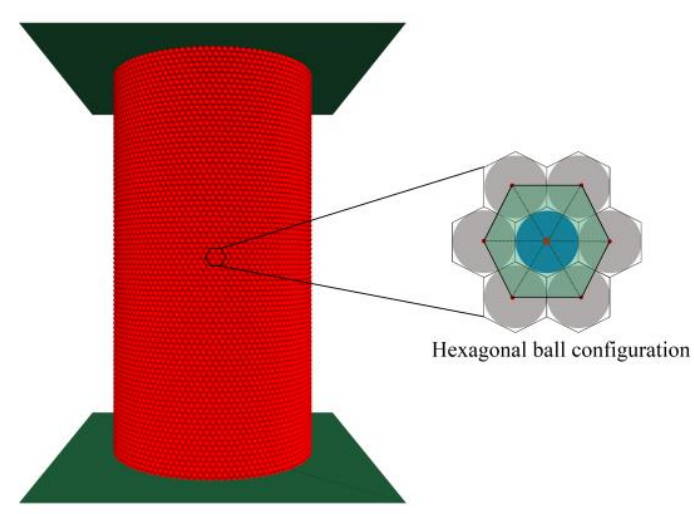

(a) Specimen before shearing

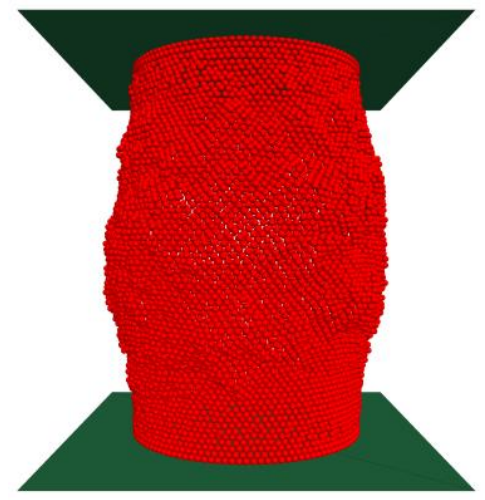

(b) Specimen after shearing

Fig. 1. Flexible boundary before and after shearing

Stack wall method: Zhao and Evans (2009) utilized several stress-controlled rigid planar walls (stack wall) to confine specimens by controlling their individual velocities by a numerical servomechanism [35]. Li et al. (2015) also used this method to simulate the torsional shear test [36]. Later, Khoubani and Evans (2018) significantly improved the flexibility of the stackedwall boundary [19], however, this approach only created a semi-flexible membrane as the walls continued to move in a horizontal direction instead of the vertical direction. Thus, the method cannot replicate the 'clamped' effects at the two ends of the triaxial specimen as discussed by Qu et al. (2019) [34].

Method of applying forces on boundary particles: Equivalent forces of confining stress are calculated and applied to the outermost particles which act as the membrane. Bardet and Proubet (1991) first introduced this technique in DEM modeling of triaxial testing [17] and later other researchers proposed algorithms to improve this method [37,38]. Cheung and O'Sullivan (2008) used the Voronoi polygon projection technique to sort out the periphery particles of the specimen to label it as a boundary to apply hydrostatic confining pressure [38]. However, the main disadvantage of this method is that the properties of membrane and the specimen particles cannot be assigned independently, and all the particles are treated as the same material. Binesh et al., (2018) proposed a new algorithm based on linking MATLAB and $\mathrm{PFC}^{3 \mathrm{D}}$ codes to identify the boundary particles by using cellular division and irradiation from the specimen's centerline; then, confining pressure is exerted directly to boundary particles via concentrated forces [39]. However, the proposed algorithm cannot replicate the Latex membrane in triaxial tests, since confining forces are exerted directly to the boundary particles [39].

Bonded-ball method: This method was used by Iwashita and Oda (1998) to model flexible membranes to simulate biaxial simulation [40]. Such a flexible membrane was composed of spherical balls that were 'glued' together with contact bonds. Bono et al. (2012), De Bono and McDowell (2014) were able to use a similar technique to model flexible membrane and thereby simulate triaxial tests $[41,42]$. Similar results were reported in other studies $[18,43]$. The bonded-ball approach allows assigning specific properties to the boundary particles (i.e. different from specimen particles). The confining pressure was applied by converting the confining pressure to equivalent forces as described by Cil and Alshibli (2014) [18]. Membrane particles are first modeled as a cage; then, specimens are created separately inside that cage. Lu et al. (2018) were able to significantly improve the flexibility of the bonded-ball flexible membrane, which confirmed the possibility of observing a typical bulging shape of the specimen during axisymmetric triaxial compression tests [43]. 
Because the bonded-ball method can assign properties to boundary particles, replicating clamped effects and allowing possible specimen bulging, we adopted this method to model a flexible membrane for our research. Specifics on modeling the bonded-ball flexible membrane follow.

Geometrical arrangement: Single-layer hexagonal packing is used to obtain the closest packing to mimic the latex membrane which has a continuous surface. Saussus and Frost (2000) noted that membrane particles should be chosen carefully to minimize the effects of the sandmembrane contact pattern [44]. Single-layer hexagonal packing reduces the bonded-ball gaps and makes the modeled membrane as smooth as possible. Hexagonal ball packing of the flexible membrane is shown in Fig. 1.

Boundary condition: In a laboratory triaxial test, the two ends of the specimen are fixed inside a rubber vessel. When confining pressure is applied, movement of the soil particles at the two ends is restricted to the radial horizontal direction, causing clamped effects [34]. To replicate the clamped effects, the radial horizontal movement of the specimen particles at the top and bottom are restricted. For this study, the specimen material was first created within the rigid cylinder which eventually was replaced by the flexible bonded-ball membrane. The membrane is defined as the boundary of the DEM model where the confining pressure is applied.

Selection of contact model: A latex membrane is "strain dominant" and cannot resist bending. Potyondy and Cundall (2004) described the bonded particle methodology, stating that a "linear contact bond" contact model can properly mimic the mechanism similar to that of the membrane [45]. In this study, the linear contact bond is used to model the flexible membrane. This linear contact bond consists of two components: the linear component and the dashpot component, and they act parallel to each other. The linear component provides linear elastic and frictional behavior but does not resist tension, while the dashpot component provides the viscous behavior that dampens force and accounts for energy loss. Contact stiffness can be divided into two microparameters, normal stiffness $\left(k_{n}\right)$ and shear stiffness $\left(k_{s}\right)$ which act as linear springs for the linear component. For the dashpot component, the dashpot force is controlled by the normal $\left(\beta_{n}\right)$ and shear $\left(\beta_{s}\right)$ critical-damping ratios. Another micro parameter is the particle friction coefficient $(\mu)$ which is responsible for developing the force that resists slip between particles.

The selection of values for normal and shear stiffness for a flexible membrane has strong effects on the deformation of the membrane. Contact stiffness of membrane particles is determined based on the equivalence of strain energy and the elastic parameters of a physical Latex membrane, which was introduced by Griffiths and Mustoe (2001) [46]. Figure 2a provides a schematic diagram of the linear contact model microparameters. Because the rubber membrane must not tear apart during testing, large values of shear and tensile strength were used, which helped the membrane withstand all possible deformations. 


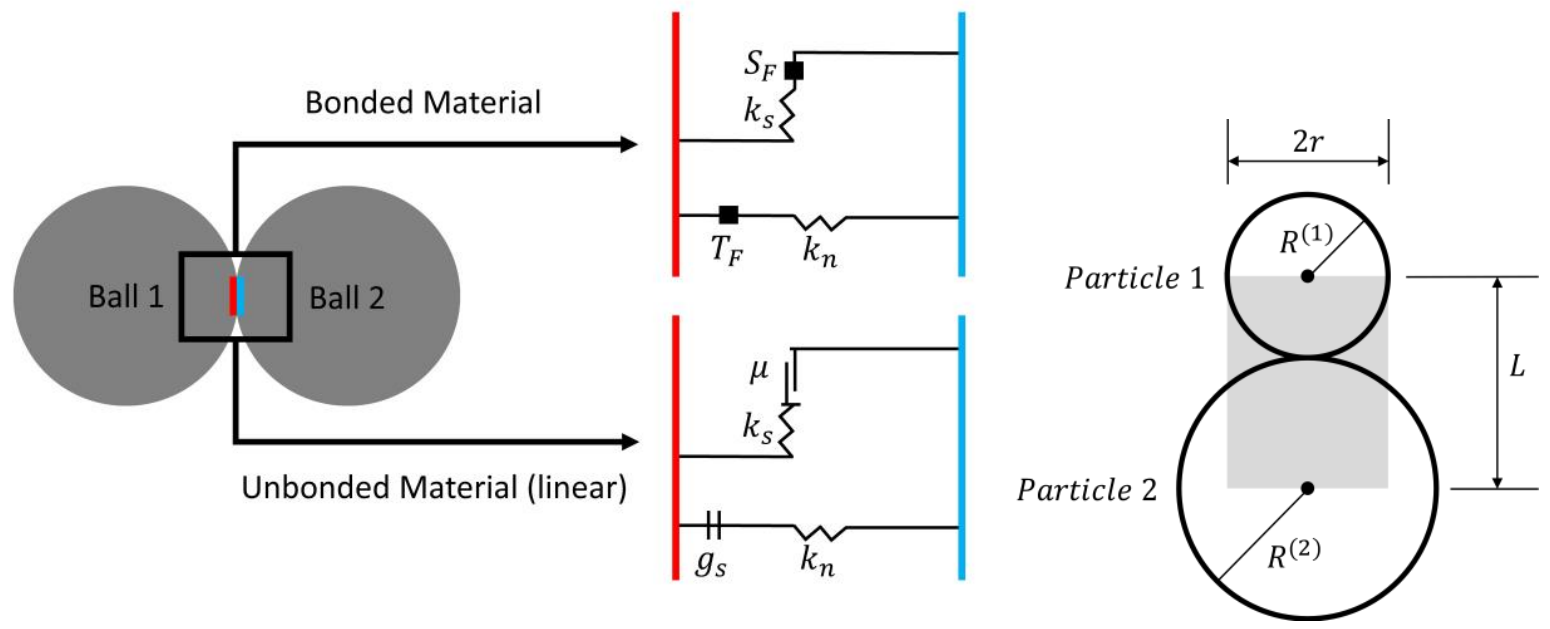

- Linear force $\left(F^{l}\right)$ can be linear elastic, bonded or frictional. Linear contact bond doesn't resist moment.

(a)

(b)

Figure 2. Micromechanical model and rheology of particle contact (a) Components of the linear contact bond and (b) volume associated with contact

\section{Methodology}

The 3D PFC, a DEM software, was utilized to study the effects of particle sizes on the soil strength and strain properties by modeling triaxial tests. Details of the approaches and methodology of the modeling follow.

Contact stiffness of the specimen: In this study, the specimen particles are considered as made from a linear material, and the particles are in contact but unbonded at contact. The contact force is divided into linear and dashpot components. The linear component provides linear elastic (no-tension), frictional behavior. Linear force is produced by linear springs with constant normal stiffness $\left(k_{n}\right)$ and shear stiffness $\left(k_{s}\right)$. The linear springs cannot sustain tension, and slip is accommodated by using the friction coefficient $(\mu)$. A more detailed description of the contact models is available in Itasca's (2014) online manual [47].

In the tested specimen, the normal stiffness $k_{n}$ and shear stiffness $k_{s}$ are set based on a specified contact deformability method. In other words, the $k_{n}$ and $k_{s}$ of a homogeneous, isotropic, and well-connected granular assembly experiencing small-strain deformation can be derived from the effective modulus $\left(E^{*}\right)$ and the normal-to-shear stiffness ratio $\left(k^{*}\right)$ at the contact [47],

$$
\begin{gathered}
k_{n}=\frac{A E^{*}}{L} ; \quad k_{s}=\frac{k_{n}}{k^{*}} \\
A=\pi r^{2} \quad(\text { in } 3 \mathrm{D})
\end{gathered}
$$

where $r$ is the smaller value of $R^{(1)}$, and $R^{(2)}$ and $L$ is the summation of $R^{(1)}$ and $R^{(2)}$ (Fig. $2 b)$.

Contact stiffness of the flexible membrane: Micro-properties of the bonded-ball membrane are calibrated to get a stress-strain response similar to that of a smooth rubber membrane surface. One solution is to match the energy that dissipates from a unit cell of the bonded-ball membrane to the energy of the corresponding rubber membrane area [48]. The center particle of a unit cell is in contact with six neighboring unit cells (Fig. 1); thus, the total energy stored in a unit cell $U_{\text {cell }}$ can be calculated as follows: 
$U_{\text {cell }}=\sum_{c}^{6} U^{c}=\frac{L_{c}^{2}}{4} \sum_{c}^{6}\left[K_{n} \varepsilon_{i j}^{c} l_{2 j} l_{2 i} \varepsilon_{k l}^{c} l_{2 k} l_{2 l}+K_{s} \varepsilon_{i j}^{c} l_{2 j}\left(l_{1 i}+l_{3 i}\right) \varepsilon_{k l}^{c} l_{2 l}\left(l_{1 k}+l_{3 k}\right)\right]$

where, $L_{c}, \varepsilon_{i j}^{c}$, and $U^{c}$ are the contact distance, equivalent strain, and equivalent strain energy for each contact $c$, respectively; and $l_{i j}$ represents the cosine angle between the global and local coordinate axes. Strain energy density can be computed from the volume of the unit cell $\left(V_{c e l l}\right)$. The surrounding area is represented as one-third of the equilateral triangle (Fig. 1) by joining two adjacent corners, and the area of each unit cell can be calculated as:

$$
v=2 \sqrt{3} r^{2}
$$

where $r$ is the radius of bonded membrane particle. If the thickness of the membrane equals to $t$, then the volume of the unit $\left(V_{\text {cell }}\right)$ cell is:

$$
V_{\text {cell }}=2 \sqrt{3} t r^{2}
$$

The distance between two particles equals two times the ball radius $\left(L_{c}=2 r\right)$, and the strain energy density is:

$$
u_{\text {cell }}=\frac{U_{c e l l}}{V_{c e l l}}=\frac{\sqrt{3}}{6 t} \sum_{c}^{6}\left[K_{n} \varepsilon_{i j}^{c} l_{2 j} l_{2 i} \varepsilon_{k l}^{c} l_{2 k} l_{2 l}+K_{s} \varepsilon_{i j}^{c} l_{2 j}\left(l_{1 i}+l_{3 i}\right) \varepsilon_{k l}^{c} l_{2 l}\left(l_{1 k}+l_{3 k}\right)\right]
$$

It is assumed that the corresponding strain tensor in a unit cell stays uniform so that the local strain is equal to the overall strain in a unit cell $\left(\varepsilon_{i j}=\varepsilon_{i j}^{c}\right)$. The stress tensor of a combined discrete body can be formulated by differentiating the strain energy density for the corresponding strain tensor as follows:

$$
\begin{gathered}
\sigma_{i j}=\frac{\partial u_{c e l l}}{\partial \varepsilon_{i j}}=\frac{1}{V} \frac{\partial \sum_{c}^{6} U^{c}}{\partial \varepsilon_{i j}}=\frac{1}{V} \sum_{c}^{6} \frac{\partial U^{c}}{\partial \varepsilon_{i j}}=\frac{1}{V} \sum_{c}^{6} \frac{\partial U^{c}}{\partial \varepsilon_{i j}^{c}}=\frac{\sqrt{3}}{3 t} \sum_{c}^{6}\left[K_{n} l_{2 j} l_{2 i} \varepsilon_{k l}^{c} l_{2 k} l_{2 l}+K_{s} l_{2 j}\left(l_{1 i}+\right.\right. \\
\left.\left.l_{3 i}\right) \varepsilon_{k l}^{c} l_{2 l}\left(l_{1 k}+l_{3 k}\right)\right]
\end{gathered}
$$

Similarly, the elastic stiffness tensor at each contact point of bonded balls is calculated by differentiating the stress tensor for the strain tensor as follows:

$$
C_{i j k l}=\frac{\partial \sigma_{i j}}{\partial \varepsilon_{k l}}=\frac{1}{V} \sum_{c}^{6} \frac{\partial^{2} U^{c}}{\partial \varepsilon_{i j}^{c} \partial \varepsilon_{k l}^{c}}=\frac{\sqrt{3}}{3 t} \sum_{c}^{6}\left[K_{n} l_{2 j} l_{2 i} l_{2 k} l_{2 l}+K_{s} l_{2 j}\left(l_{1 i}+l_{3 i}\right) l_{2 l}\left(l_{1 k}+l_{3 k}\right)\right]
$$

As a result, the analytical solution for calculating the normal stiffness $\left(K_{n}\right)$ and shear stiffness $\left(K_{S}\right)$ of the membrane particles can be formulated as

$$
\begin{aligned}
& K_{n}=\frac{E t}{\sqrt{3}(1-v)} \\
& K_{s}=\frac{E t(1-3 v)}{\sqrt{3}\left(1-v^{2}\right)}
\end{aligned}
$$

where $E, t$, and $v$ are the elastic membrane modulus, the thickness of the membrane, and Poisson ratio in the whole flexible membrane system, respectively [34].

Steps for modeling triaxial tests implementing bonded-ball flexible membrane: This algorithm was developed by incorporating the membrane forming technique described by $\mathrm{Lu}$ et al. (2018) and Qu et al. (2019) [43,34]. The steps are as follows.

1. Specimen particles are generated in a rigid cylindrical wall.

2. All the linear and rotational velocities of the specimen particles are set to zero; then, the original rigid cylindrical wall is deleted.

3. A hexagonal bonded-ball membrane is installed, and the linear contact bond is activated between membrane particles. 
4. The velocity of membrane particles is fixed (i.e., no movements). Start an "iteration" process allowing the specimen particles to move freely until a static equilibrium state is achieved.

5. An equivalent static force is converted from the confining pressure and applied to the membrane particles to maintain the constant hydrostatic pressure in the specimen.

6. Perform iterations until the whole system achieves a static equilibrium.

7. The vertical loading is applied to the specimen using a servomechanism. The servomechanism is implemented by controlling the movement of the walls using a constant velocity.

8. A rate displacement of $0.05 \mathrm{~mm} / \mathrm{s}$ is applied to the top and bottom wall, which is slow enough to maintain a quasi-static condition.

9. The triaxial loading process stops when the axial strain reaches the prescribed value of $6 \%$.

Stress-strain calculations for the specimen with the flexible membrane: Stress is a continuum quantity and does not exist at any point in a discrete medium of particle assembly. Instead, contact forces and displacements are used to study the material behaviors on a microscale in the PFC model. The average stress in a certain region with volume $V$ in the static condition is:

$$
\bar{\sigma}=-\frac{1}{V} \sum_{N_{c}} F^{(c)} \times L^{(c)}
$$

where $N_{c}$ is the total number of contacts within the volume, $F^{(c)}$ is the contact force vector, and $L^{(c)}$ is the branch vector joining the centroids of the two bodies in contact. The negative sign indicates the compressive stress to the system.

A bonded-ball flexible membrane has an uneven surface, which makes it more difficult to calculate the volume of the deformed specimen compared to that of a rigid membrane. The logarithmic value of strain is useful to quantify the distortion due to loading in this case. The axial strain, $\varepsilon_{1}$ can be calculated as:

$$
\varepsilon_{1}=-\int \delta \varepsilon=-\int_{H_{0}}^{H} \frac{\delta H}{H}=-\ln \left(\frac{H}{H_{0}}\right)=\ln \left(\frac{H_{0}}{H}\right)
$$

and, the volumetric strain, $\varepsilon_{V}$ can be calculated as:

$$
\varepsilon_{V}=-\int \delta \varepsilon_{V}=-\int_{V_{0}}^{V} \frac{\delta V}{V}=-\ln \left(\frac{V}{V_{0}}\right)=\ln \left(\frac{V_{0}}{V}\right)
$$

where $H$ and $V$ are the current height and volume of the specimen, and $H_{0}$ and $V_{0}$ are the original height and volume of the specimen before starting the test. Here, compression is positive.

\subsection{Model development criteria}

In a DEM triaxial test simulation, distinct differences exist between the membrane particles and the specimen particles, including size, stiffness, and geometric arrangement. To obtain more accurate results on the stress-strain responses of the specimens with a bonded-ball flexible membrane, the following criteria were maintained:

Specimen particle size and membrane particle size: Qu et al. (2019) performed sets of uniaxial tension tests and compared them with the analytical solution to observe the modeling efficiency [34]. They concluded that the numerical model with a flexible bonded-ball membrane can have less than 5\% error if the following empirical rule of radius ratio is used:

$$
35 \leq \frac{R}{r} \leq 100
$$


where $R$ is the test cylinder radius and $r$ is the membrane ball radius. When the radius ratio is less than 35, larger gaps exist between membrane particles, and the results become unsatisfactory. On the other hand, when the radius ratio is more than 100 , the number of elements is significantly large, which leads to exceptionally high computational costs.

As in a typical laboratory triaxial test, the diameter of the specimen (or the inner diameter of test cylinder $D$ ) should be at least six times greater than the maximum particle sizes $d_{\text {max }}$. Membrane particles should be small enough to achieve the closest packing, which can be achieved by using smaller sized membrane particles, but the trade-off is the higher computational time. To get satisfactory results at a reasonable computation time, Bono et al. (2012) suggested that membrane particle size may be taken as one-third of the specimen particles [41]. This ratio is used in this study.

Particle friction coefficient: The local friction coefficient of sand has a strong effect on the deformation of particles [7], and the contact stiffness and friction coefficient have strong effects on shear testing results $[49,50]$. For the calibration of sand microparameters using DEM simulations, to match the critical-state shear stress, Ahlinhan et al. (2018) used a particle friction coefficient value greater than 1.0 [51]. A high value on the particle friction coefficient can compensate for the low rotational and shearing resistance of spherical particles. The high value can also account for the irregularity effects on the particle shape - to possibly increase the overall shearing resistance between spherical particles. For this study, a lower friction coefficient of 0.3 was chosen as a starting point for the model calibration, and later, to increase the interlocking between spherical particles, a higher friction coefficient larger than 1.0 was used to study the stress-strain relationship.

Application of confining pressure: As like a laboratory triaxial test, the hydrostatic confining pressure is applied to the membrane as isotropic stress in simulating of the test. For the bondedball flexible membrane approach, the confining pressure needs to be converted to the equivalent static force that acts uniformly from all directions. Since the membrane is packed by hexagonal ball configuration, the whole system consists of a set of triangular bodies (Fig. 1). Hence, the resultant force acting on each particle can be computed from six neighboring particle triangles:

$$
F^{*}=\frac{\sigma_{\text {static }}}{3} \sum_{i}^{6} n_{i} S_{i}
$$

where $\sigma_{\text {static }}$ is the confining stress; $n_{i}$ and $S_{i}$ are the normal direction and area of the $i^{\text {th }}$ triangle, respectively [34].

\section{Analyses, Results and Discussions}

For a DEM model, there exists micro-structural input parameters that cannot be measured directly in the laboratory; thus, a common approach is to calibrate or back-calculate these micro parameters by simulating laboratory tests and adjusting these parameters to match with the experimental data. Note that the stress-strain responses of the numerical experiment are sensitive to two or more micro parameters [52-54], and there is no unique solution since more than one combination of the parameters may result in a similar stress-strain response. Adjusting the micro parameters was necessary for model calibration and was achieved by matching the simulation results with the experimental data. Sensitivity analyses were carried out to identify the effects of the microparameters on the stress-strain responses of granular soils, and based on the results, micro-parameters were selected for use in the DEM model. The model was verified using experimental data, and the analysis were carried out for the stress-strain response of the simulated triaxial tests.

\subsection{Sensitivity analysis}


Sensitivity analyses were performed to identify the effects of microparameters on the stressstrain responses of granular soils. Two sets of numerical simulations were performed. Set 1 includes cases [1.1] to [1.5] with varying particle stiffness. Set 2 includes cases [2.1] to [2.5] with varying particle friction coefficients. Inputs for the sensitivity analysis are presented in Table 1 . The base values of the particle stiffness and friction coefficient were set to $10^{6} \mathrm{~N} / \mathrm{m}$ and 0.3 respectively. Confining pressure, $\sigma_{3}$, was at $100 \mathrm{kPa}$.

For Set 1, an increase was observed in particle normal stiffness and shear stiffness resulting in an increase in the material elastic modulus, shown as the slopes of the stress-strain curve increases (Fig. 3a). However, changes in the normal and shear stiffness does not affect the peak strength of the curves, since there is no clear trend for the peak values in the different cases. For Set 2, it was observed that increasing the friction coefficient causes an increase in peak strength (Fig. 3b). However, the increasing friction coefficient does not affect the material elastic modulus, since the slope of the curves is the same. Furthermore, an increase in friction coefficient does not affect the residual stresses of the curves either. An application of this finding is that, for the model calibration, if the desired elastic modulus is reached, then the particle friction coefficient is adjusted to match the peak strength of the numerical results with the experimental result.

Table 1 . Inputs for sensitivity analysis

\begin{tabular}{cccc}
\hline Numerical Simulations & $k_{n}(N / m)$ & $k_{s}(N / m)$ & $\mu(-)$ \\
\hline Base value & $10^{6}$ & $10^{6}$ & 0.3 \\
Case [1.1] & $k_{n 1.1}=0.1 k_{n}$ & $k_{s 1.1}=0.1 k_{s}$ & $\mu_{1.1}=\mu$ \\
Case [1.2] & $k_{n 1.2}=0.25 k_{n}$ & $k_{s 1.2}=0.25 k_{s}$ & $\mu_{1.2}=\mu$ \\
Case [1.3] & $k_{n 1.3}=0.5 k_{n}$ & $k_{s 1.3}=0.5 k_{s}$ & $\mu_{1.3}=\mu$ \\
Case [1.4] & $k_{n 1.4}=0.75 k_{n}$ & $k_{s 1.4}=0.75 k_{s}$ & $\mu_{1.4}=\mu$ \\
Case [1.5] & $k_{n 1.5}=k_{n}$ & $k_{s 1.5}=k_{s}$ & $\mu_{1.5}=\mu$ \\
Case [2.1] & $k_{n 2.1}=k_{n}$ & $k_{s 2.1}=k_{s}$ & $\mu_{2.1}=\mu$ \\
Case [2.2] & $k_{n 2.2}=k_{n}$ & $k_{s 2.2}=k_{s}$ & $\mu_{2.2}=1.33 \mu$ \\
Case [2.3] & $k_{n 2.3}=k_{n}$ & $k_{s 2.3}=k_{s}$ & $\mu_{2.3}=2.33 \mu$ \\
Case [2.4] & $k_{n 2.4}=k_{n}$ & $k_{s 2.4}=k_{s}$ & $\mu_{2.4}=3.33 \mu$ \\
Case [2.5] & $k_{n 2.5}=k_{n}$ & $k_{s 2.5}=k_{s}$ & $\mu_{2.5}=5 \mu$ \\
\hline
\end{tabular}




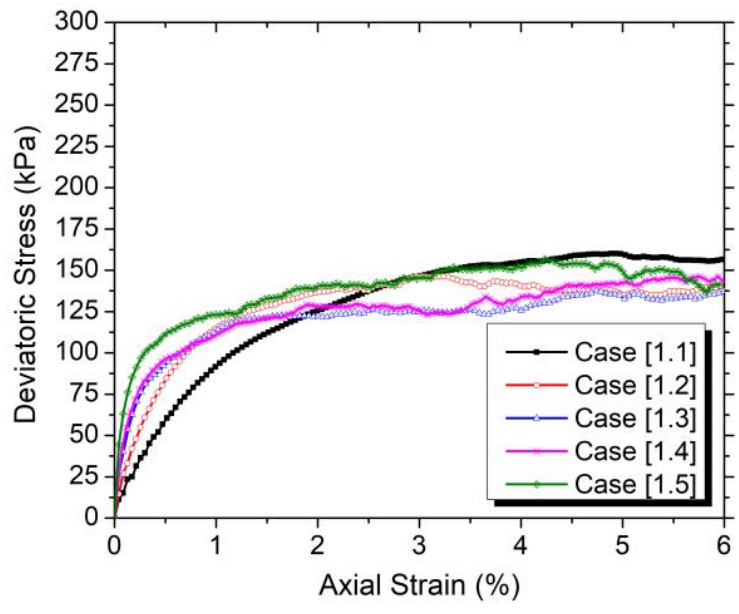

(a)

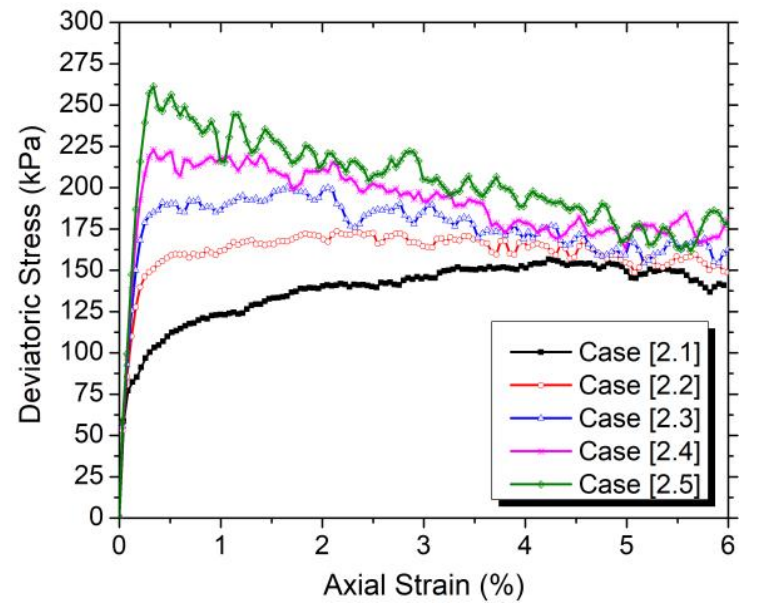

(b)

Figure 3. Stress-strain curves from sensitivity analyses. (a) Stress-strain curves for Set 1 with different particle stiffnesses, showing that the elastic modulus increases with the increasing the particle stiffness and (b) stress-strain curves for Set 2 with different particle friction coefficients show how peak strength increases with increasing the particle friction coefficient.

\subsection{Calibrating and Validating the Model}

This study adopted experimental triaxial test data of steel balls performed by Lin et al. (2016) to calibrate and validate the 3D numerical model [55]. Numerical stiffness parameters such as normal stiffness $k_{n}$ and shear stiffness $k_{s}$ were determined to match the elasticity modulus (stress-strain curve for strain less than 1\%) of the steel material. After achieving the target elasticity modulus, the particle-particle friction coefficient $(\mu)$ was varied to adjust the peak stress of the numerical results.

For the model validation, three simulation tests were run at different confining pressures of 100,300 , and $500 \mathrm{KPa}$. Inputs of microscopic parameters used in the model include normal stiffness of $7 \times 10^{5} \mathrm{~N} / \mathrm{m}$, shear stiffness of $3 \times 10^{5} \mathrm{~N} / \mathrm{m}$, and friction coefficient of 0.3 . Obtained stress-strain curves of the three simulated tests are presented along with the experimental test data from Lin and Zhang (2016) [55] in Figure 4a. The curves are almost identical showing the same behaviors of the simulated specimens as of the experimental specimens. Our model's precision was tested by running three samples two time each. These tests showed the stress-strain curves of the repeated runs to be identical (Fig. 4b). This agreement verified the PFC DEM model for the analysis. The developed model can be used to predict the nonlinear stress-strain behavior of granular materials. 


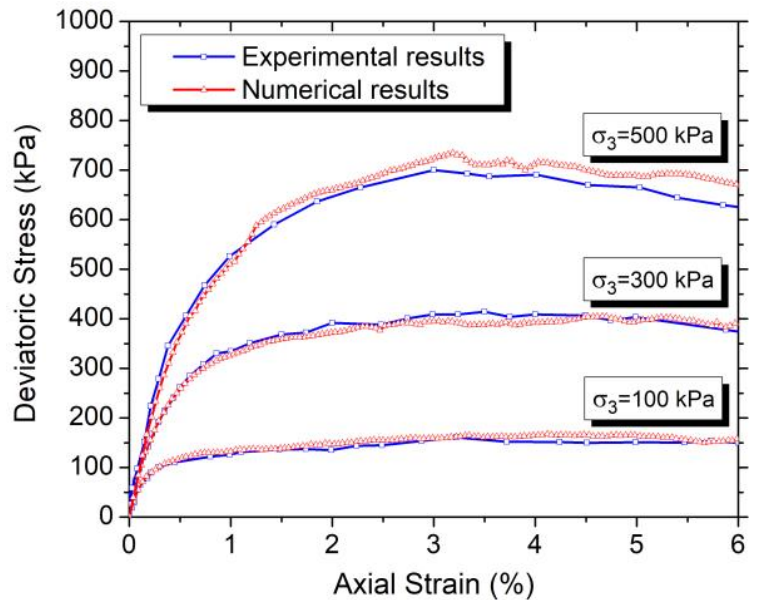

(a)

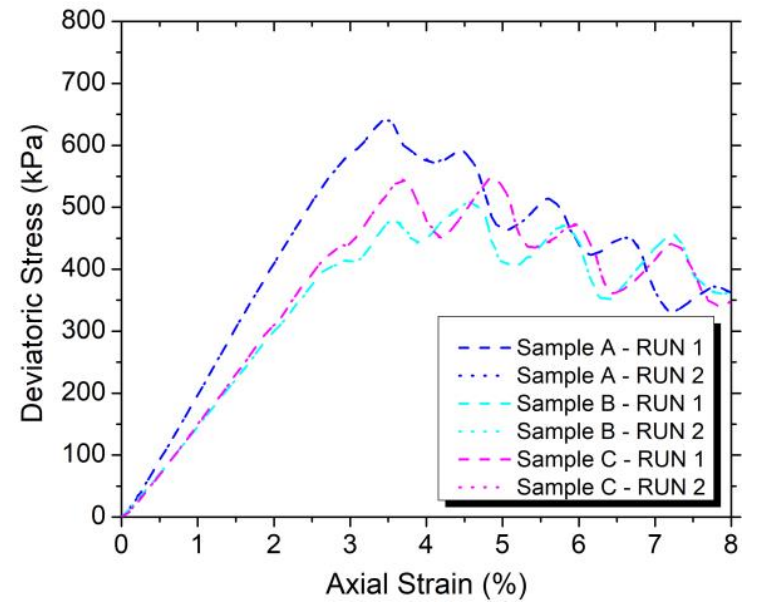

(b)

Fig. 4. Validation and precision of the DEM model. (a) Comparison of experimental and numerical data showing the model's accuracy and (b) repeated runs with identical results showing the model's precision.

\subsection{Effects of particles size on deviatoric stress, friction angle, and dilatancy angle}

Our model shows its potential to isolate individual factors that affect soil strength and strain properties. These factors may include particle size, shape, and surface smoothness. For this study, the effects of particle size on stress-strain behaviors, deviatoric stress, friction angle, and dilatancy angle were investigated. Four scenarios were considered covering soil with randomly created particle sizes, soil with uniform particle size, and two soils, each with two different particle sizes, as follows:

- Case I: Soil with randomly created particle sizes. In this case, the minimum particle size was not changed while the maximum particle size was increased. In between are randomly created particle sizes. The focus here was a study on the effects of the presence of larger particle sizes and the mean particle size $D_{50}$ on the three parameters of deviatoric stress, friction angle, and dilatancy.

- Case II: Soil with uniform spherical particles. The particle size was increased from $4 \mathrm{~mm}$ to $12 \mathrm{~mm}$ to study the effects of particle size on the three parameters.

- Cases III and IV: The focus here was on soil consisting of only two particle sizes, the smaller diameter, $D_{S}$, and larger diameter, $D_{L}$. Smaller particles with diameter $D_{S}$ make up $90 \%$ of the specimen volume. Larger particles with diameter $D_{L}$ make up $10 \%$ of the volume. Starting with uniform soil $\left(D_{S}=D_{L}\right)$ the parameters for both cases follow:

- for Case III: $D_{S}$ was kept unchanged, and the larger diameter $D_{L}$ was increased from 4 $\mathrm{mm}$ to $12 \mathrm{~mm}$

- for Case IV: $D_{L}$ was kept unchanged, and smaller diameter $D_{S}$ was decreased from 12 $\mathrm{mm}$ to $4 \mathrm{~mm}$.

Soil specimens were contained in cylinders made up of bonded balls to simulate flexible membranes. The cylinders were $140 \mathrm{~mm}$ high and $70 \mathrm{~mm}$ in diameter. Microscopic parameters used in the model are shown in Table 2. The axial strain rate was $0.05 \mathrm{~mm} / \mathrm{s}$, small enough to consider the soil specimen as being in a quasi-static condition. The load is quasi-static and is applied slowly to maintain a low strain rate, allowing the system to deform slowly so that the inertia force developed in the system is negligible. The benefit of maintaining a quasi-static condition is to keep the internal pressure developed from the external compression constant and uniform. 
Table 2. Microscopic parameters

\begin{tabular}{lcl}
\hline \multicolumn{1}{c}{ Properties } & Test specimen & \multicolumn{1}{c}{ Membrane } \\
\hline Contact model & Linear & Linear contact bond \\
Minimum ball radius $(\mathrm{mm})$ & 3.0 & 1.0 \\
Maximum ball radius $(\mathrm{mm})$ & 6.0 & 1.0 \\
Density $\left(\mathrm{kg} / \mathrm{m}^{3}\right)$ & 2650 & 2000 \\
Friction coefficient & 4.0 & 0 \\
Effective modulus $(\mathrm{Pa})$ & $3 \times 10^{7}$ & $1.25 \times 10^{6}$ \\
Poisson ratio & - & 0.2 \\
Normal bond strength $(\mathrm{Pa})$ & - & $10^{100}$ \\
Shear bond strength $(\mathrm{Pa})$ & - & $10^{100}$ \\
$k_{n} / k_{s}$ & 1.0 & $k_{n}$ and $k_{s}$ were calculated based on the \\
& & Poisson ratio, membrane thickness, \\
& & and membrane modulus \\
\hline
\end{tabular}

Analysis for Case I: Effects of larger particle size and $D_{50}$ on deviatoric stress, friction angle, and dilatancy were studied by simulating triaxial tests for three soils with three specimens $\mathrm{T} 1$, $\mathrm{T} 2$, and T3. The minimum diameter was kept at $6 \mathrm{~mm}$, and the maximum diameter was increased to $8 \mathrm{~mm}, 10 \mathrm{~mm}$, and $12 \mathrm{~mm}$ (Table 3). Spherical particles with different diameters in between were randomly created to increase $D_{50}$. All specimens have the same porosity. The number of randomly created particles in each sample ranges from 863 to 2559 . The grain size distributions for the specimens are shown in Fig. 5.

Table 3. Numerical specimen characteristics

\begin{tabular}{|c|c|c|c|}
\hline $\begin{array}{l}\text { Specimen } \\
\text { Code }\end{array}$ & $\begin{array}{l}\text { Minimum } \\
\text { diameter, } \\
D_{\text {min }}(\mathrm{mm})\end{array}$ & $\begin{array}{l}\text { Maximum } \\
\text { diameter, } \\
D_{\max }(\mathrm{mm})\end{array}$ & $\begin{array}{r}D_{50} \\
(\mathrm{~mm})\end{array}$ \\
\hline $\mathrm{T} 1$ & 6 & 8 & 6.87 \\
\hline $\mathrm{T} 2$ & 6 & 10 & 7.81 \\
\hline T3 & 6 & 12 & 9.13 \\
\hline 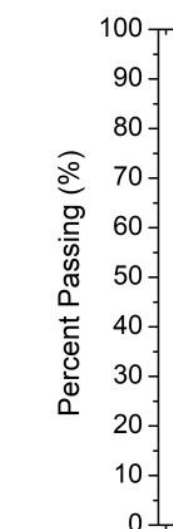 & & & $\begin{array}{r}-\mathrm{T} 1 \\
-\mathrm{T} 2 \\
-\mathrm{T} 3 \\
\end{array}$ \\
\hline & 5 & $\begin{array}{ccc}7 & 8 & 9 \\
\text { Size }(\mathrm{mm}) & \end{array}$ & \\
\hline
\end{tabular}

Fig. 5. Grain size distribution curves for soil specimens.

Figure 6a.i shows stress-strain responses of the three specimens at a low confining pressure of $35 \mathrm{kPa}$. Specimen T1's peak stress is the lowest at $130 \mathrm{kPa}$. The highest peak stress value was at $142 \mathrm{kPa}$ for Specimen T3 which has the largest maximum size and highest $D_{50}$. An 
approximately $8 \%$ increase in the peak deviatoric stress was observed by varying particle sizes, showing the dependency of the shear strength on the particle diameter.

To obtain the soil strength parameter of the friction angle for the soils, additional tests with higher confining pressures of $70 \mathrm{kPa}$ and $150 \mathrm{kPa}$ were simulated. Similar responses were observed confirming that for this Case I, specimens with larger maximum size and $D_{50}$ generate higher strengths (Fig. 6b.i and 6c.i). In the post-peak zone of the stress-strain curves, the specimens exhibited strain-softening behavior for all three confining pressures.

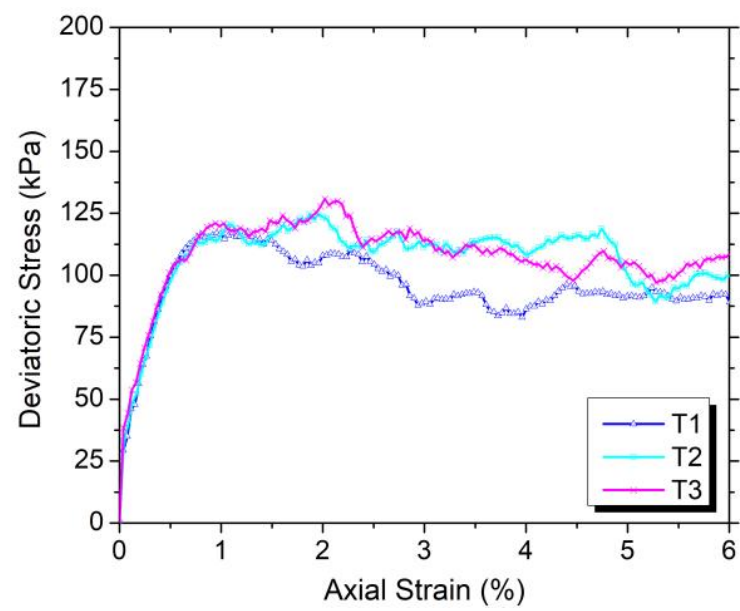

(i) Stress-strain curves

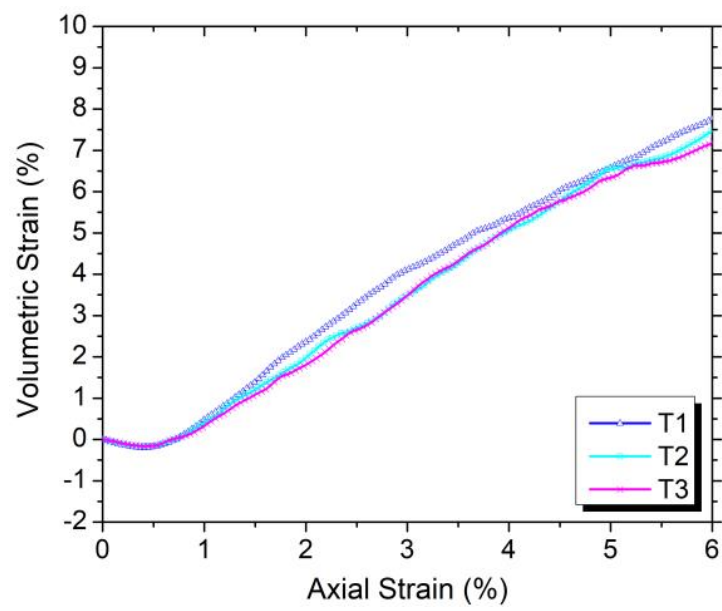

(ii) Volumetric strain.

(a) Confining pressure $\sigma_{3}=35 \mathrm{kPa}$.

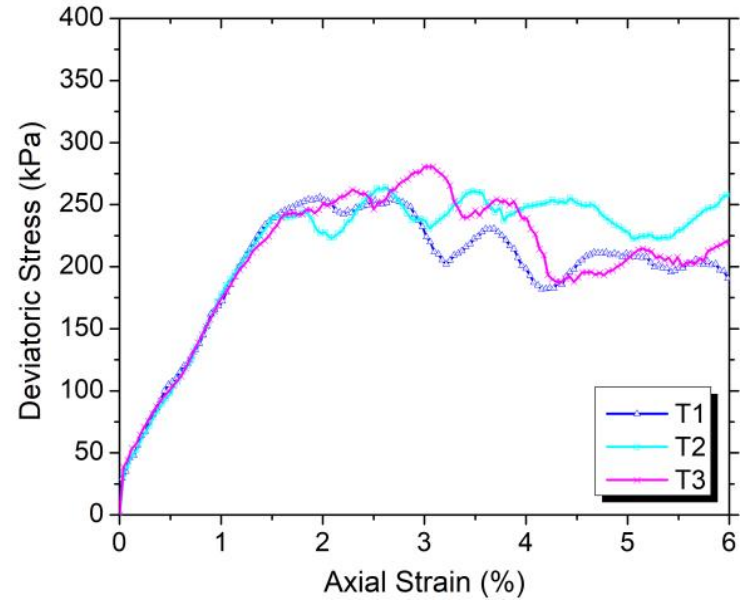

(i) Stress-strain curves.

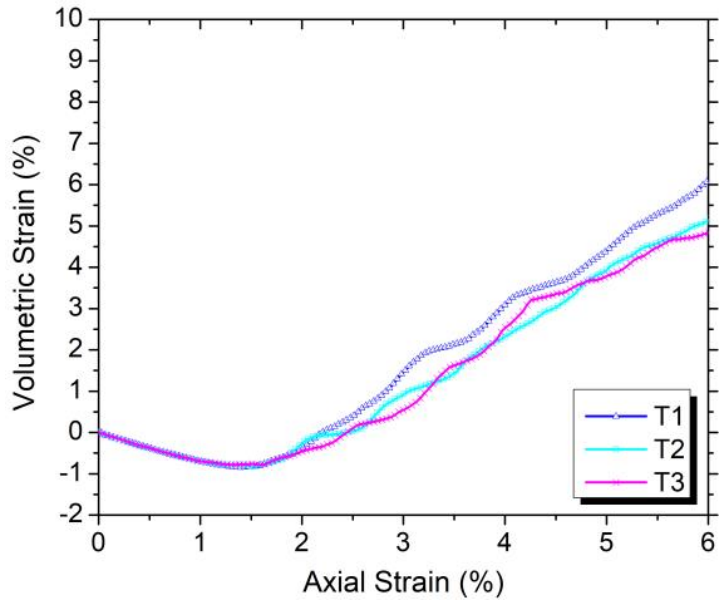

(ii) Volumetric strain.

(b) Confining pressure $\sigma_{3}=70 \mathrm{kPa}$.
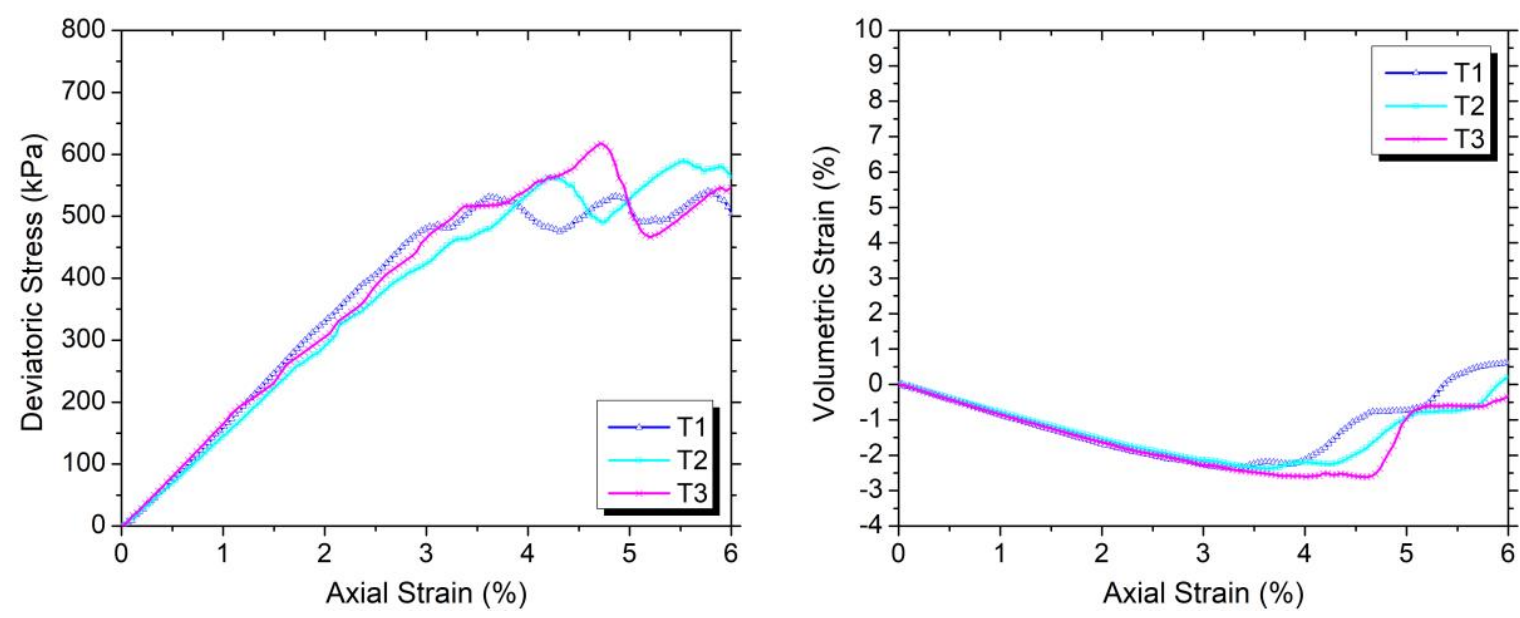
(i) Stress-strain curves.

(ii) Volumetric strain.

(c) Confining pressure $\sigma_{3}=150 \mathrm{kPa}$.

Fig. 6. Case I: stress-strain relation and volume change.

Figure 7 presents Mohr's-circles and failure envelopes for the three soil specimens. The angle of internal friction $(\varphi)$ determined from the envelopes is $38.1^{\circ}$ for $\mathrm{T} 1$ and increases to $42.3^{\circ}$ for specimen T3 (Table 4). For these soils with the same minimum particle size, the larger the maximum particle size is, the higher the internal friction angle is. This is consistent with the research results reported by Dai et al. (2016) and Harehdasht et al. (2017) [56,57]. The finding that shear strength increases with the increase of coarse content in the specimen is in consistent with finding from Xiaofeng et al. (2013), and Kim and Ha (2014) [27,28].

Note that each envelope is tangent with the three circles, meaning that, as in theory for cohesionless soil only one test is needed to determine the soil's failure envelope and friction angle instead of requiring several tests for a soil as in the laboratory. For the rest of the analysis, only one test at one confining pressure is analyzed to obtain the friction angle for a soil specimen.

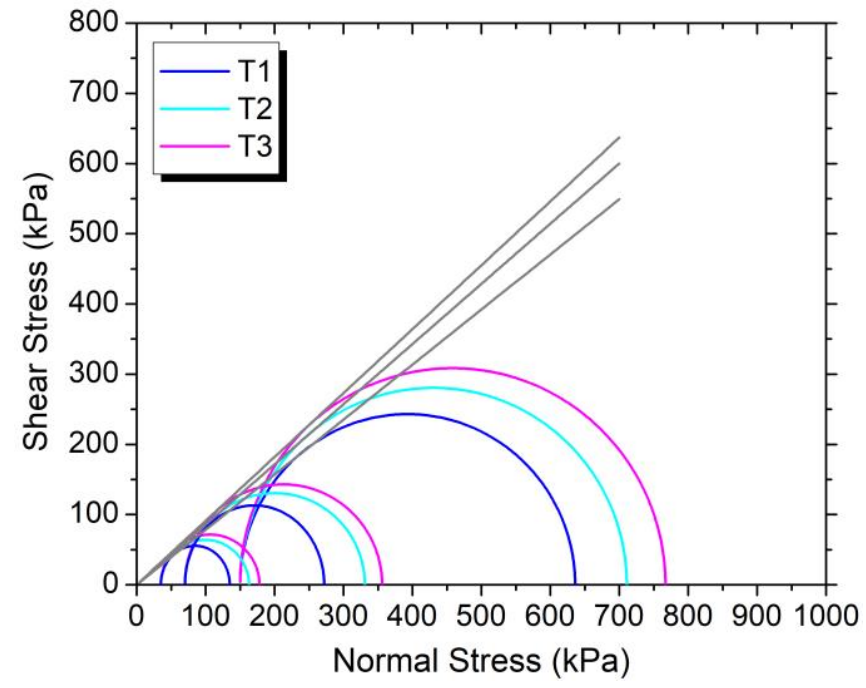

Fig. 7. Mohr's Circles generated for T1, T2, and T3 with the Mohr-Coulomb failure envelopes to obtain the friction angles.

Table 4. Angle of internal friction and dilatancy angle.

\begin{tabular}{cccccc}
\hline \multirow{2}{*}{$\begin{array}{c}\text { Specimen } \\
\text { Code }\end{array}$} & \multicolumn{3}{c}{ Normal Stress and Shear Stress $(\mathrm{kPa})$} & & \\
\cline { 2 - 3 } & $\sigma_{3}=150$ & $\sigma_{3}=70$ & $\sigma_{3}=35$ & & $\Psi\left(^{\circ}\right)$ \\
\hline $\mathrm{T} 1$ & $\sigma_{1}=636$ & $\sigma_{1}=272$ & $\sigma_{1}=135$ & 38.1 & 9.7 \\
$\mathrm{~T} 2$ & $\sigma_{1}=711$ & $\sigma_{1}=331$ & $\sigma_{1}=163$ & 40.6 & 12.9 \\
$\mathrm{~T} 3$ & $\sigma_{1}=767$ & $\sigma_{1}=356$ & $\sigma_{1}=178$ & 42.3 & 15.1 \\
\hline
\end{tabular}

Volume change was observed for all specimens (Fig. 6). At the initial stage of triaxial shearing, all the tests share the same rate of volume contraction. This trend is due to the elastic deformation which dominates initial shearing. However, in the post-peak zone, a noticeable difference in dilation occurs. The changes in dilatancy angles for the three specimens were 
determined from $9.7^{\circ}$ to $15.1^{\circ}$ (Table 4). Dilatancy angles are increased by $35 \%$ when particle sizes are increased in these randomly created specimens, showing the presence of larger particle sizes has strong impacts on the dilatancy of granular soil. Additional observation is the effects of confining pressures, higher confining pressure results in higher deviatoric stress, and failure occurs at larger axial strains. Also, higher confining pressure causes dilation to occur at a larger axial strain. Expansion/dilation starts to occur at around $0.6 \%$ axial strain when confining pressure is at $35 \mathrm{KPa}$, and may reach up to $4 \%$ with the confining pressure of 150 $\mathrm{KPa}$.

The observation that those specimens, with the same minimum particle size and same porosity but have the presence of larger particles, being capable of producing a higher resistance to shear can be qualitatively explained. During shear testing, the external load is transferred in a granular specimen by forming local contact forces at contact points. Particles in the granular specimen gradually move to a new arrangement during shearing. The relative movement of larger particles is less than that of the smaller particles since the smaller particles have the tendency to fill in the voids. The movements lead to continuous breaks and a reconstruction of contacts. Since the load is strain-controlled, and the larger particles move less, the stress concentrates more and more on the larger particles' contacts, resulting in more load is carried by the larger particles. For this Case I soil with gradation, the deviatoric stress, friction angle and dilatancy angle all increased as the mean particle size $D_{50}$ increased.

Analysis for Cases II, III and IV: Soil for Case II has uniform spherical particles. Soil for Cases III and IV has two particle sizes, smaller particles with diameter $D_{s}$, which makes up $90 \%$ of the specimen volume, and larger particles with diameter $D_{L}$, which makes up the other $10 \%$ of the specimen volume. Starting with $D_{s}$ being equal to $D_{L}$, for Case III, $D_{s}$ was kept at $4 \mathrm{~mm}$ and $D_{L}$ was increased from $4 \mathrm{~mm}$ to $12 \mathrm{~mm}$. For Case IV, $D_{L}$ was kept at $12 \mathrm{~mm}$, and $D_{s}$ was reduced from $12 \mathrm{~mm}$ to $4 \mathrm{~mm}$ (Table 5). All soil specimens have the same porosity of 0.38 , under a confining pressure of $150 \mathrm{kPa}$. The number of randomly created particles in each sample ranges from 408 to 10,443 .

For Case II: Studies considered five soils made up of uniform spherical particles. When increasing the size of the particles from $4 \mathrm{~mm}$ to $12 \mathrm{~mm}$, the peak deviatoric stress, internal friction angles, and dilatancy angles - all decreased. The deviatoric stress reduced by almost $37 \%$, and the friction angle decreased from $36.3^{\circ}$ to $28.5^{\circ}$. The dilatancy angle decreased from $5.1^{\circ}$ to $0^{\circ}$ as shown in Fig. 8a and 9a. Thus, for Case II, the three parameters decrease with an increasing $D_{50}$. Conversely, in the previous analysis of Case I for soil with gradation, the specimen's peak deviatoric stress, internal friction angle, and dilatancy angle increased with an increasing $D_{50}$. The finding from this study that the angle of internal friction decreases with the increase of uniform particle size disagrees with a conclusion from Islam et al. (2011), which was based on a series of direct shear tests. They stated that with an increase in particle size, the friction angle increases for uniform sands and graded sands [32]. However, our finding is in agreement with two older studies by Kirpatric (1965) and Marschi et al. (1972) [25,26].. Our stance on this issue can be explained by noting the reduction in deviatoric stress and friction angle with the increasing particle sizes. This observation is based on uniform soil with spherical particles, wherein the increasing particle size reduces the number of contact points in the specimens, thereby causing a reduction in the soil's strength.

The fittings of the peak deviatoric stress, internal friction angles, and dilatancy angles as functions of particle size are presented in Figure 9a. The relationships between the three parameters and particle size are inversely linear. These relationships can help predict the changes in the parameters with particle size. 
For Case III: The smaller diameter $D_{S}$ was kept unchanged at $4 \mathrm{~mm}$, and the larger diameter $D_{L}$ is increased, peak deviatoric stress, internal friction angle, and dilatancy angle all increased. When $D_{L}$ increased from 4 to $12 \mathrm{~mm}$. The deviatoric stress increased $47 \%$, and the friction angle increased from $36.3^{\circ}$ to $43.0^{\circ}$. The dilatancy angle increased significantly from $5.1^{\circ}$ to $16.0^{\circ}$. This means that for Case III, the three parameters increased with the increasing $D_{50}$. Direct relationships can be clearly seen between the larger particle size $D_{L}$ with the deviatoric stress, friction angle, and dilation angle. This is due to the presence of larger particles in the specimen with effects that are as similar to those described in Case I. The fitting obtained in Fig. 9b shows the three relationships to be almost linear.

For Case IV: When the larger diameter $D_{L}$ was kept unchanged, and the smaller diameter $D_{S}$ was decreased, the deviatoric stresses, friction angle, and dilatancy angle of the soil increased. When $D_{s}$ decreased from 12 to $4 \mathrm{~mm}$, the deviatoric stress increased by more than $120 \%$, the friction angle increased significantly from $28.5^{\circ}$ to $43.0^{\circ}$, and the dilatancy angle increased from $0^{\circ}$ to $16.0^{\circ}$. Here, the three parameters decreased with the increasing $D_{50}$. This is the reverse relationship similar to Case I. Again, linear relationships were observed between $D_{S}$ the particles in the 90\% volume and the three parameters, which are shown in Fig. 9c. 
Table 5. Deviatoric stress, internal friction angle, and dilatancy angle

\begin{tabular}{|c|c|c|c|c|}
\hline & Diameter & $\Delta \sigma(k P a)$ & $\varphi\left(^{\circ}\right)$ at peak & $\Psi\left({ }^{\circ}\right)$ \\
\hline \multirow{5}{*}{ 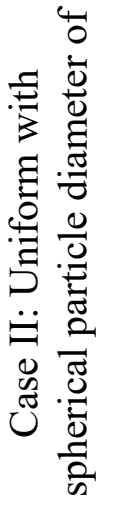 } & $4 \mathrm{~mm}$ & 435 & 36.3 & 5.1 \\
\hline & $6 \mathrm{~mm}$ & 372 & 33.6 & 4.2 \\
\hline & $8 \mathrm{~mm}$ & 338 & 32.0 & 2.3 \\
\hline & $10 \mathrm{~mm}$ & 317 & 30.8 & 0.9 \\
\hline & $12 \mathrm{~mm}$ & 274 & 28.5 & 0 \\
\hline \multirow{5}{*}{ 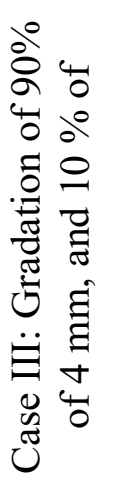 } & $4 \mathrm{~mm}$ & 435 & 36.3 & 5.1 \\
\hline & $6 \mathrm{~mm}$ & 481 & 38.0 & 9.6 \\
\hline & $8 \mathrm{~mm}$ & 514 & 39.2 & 11.1 \\
\hline & $10 \mathrm{~mm}$ & 613 & 42.2 & 15.0 \\
\hline & $12 \mathrm{~mm}$ & 640 & 43.0 & 16.0 \\
\hline \multirow{5}{*}{ 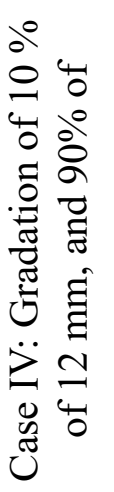 } & $4 \mathrm{~mm}$ & 640 & 43.0 & 16.0 \\
\hline & $6 \mathrm{~mm}$ & 540 & 40.0 & 12.1 \\
\hline & $8 \mathrm{~mm}$ & 473 & 37.7 & 9.2 \\
\hline & $10 \mathrm{~mm}$ & 362 & 33.1 & 3.6 \\
\hline & $12 \mathrm{~mm}$ & 274 & 28.5 & 0 \\
\hline
\end{tabular}




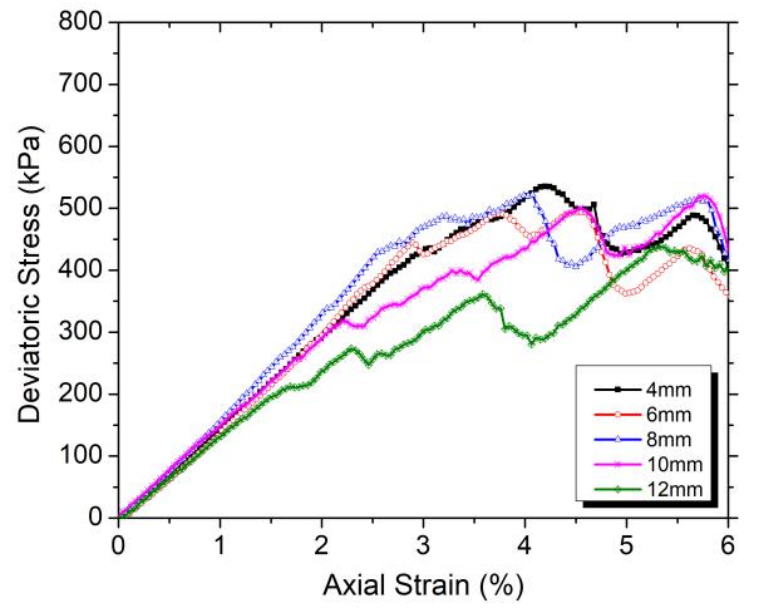

(i) Stress-strain curves.

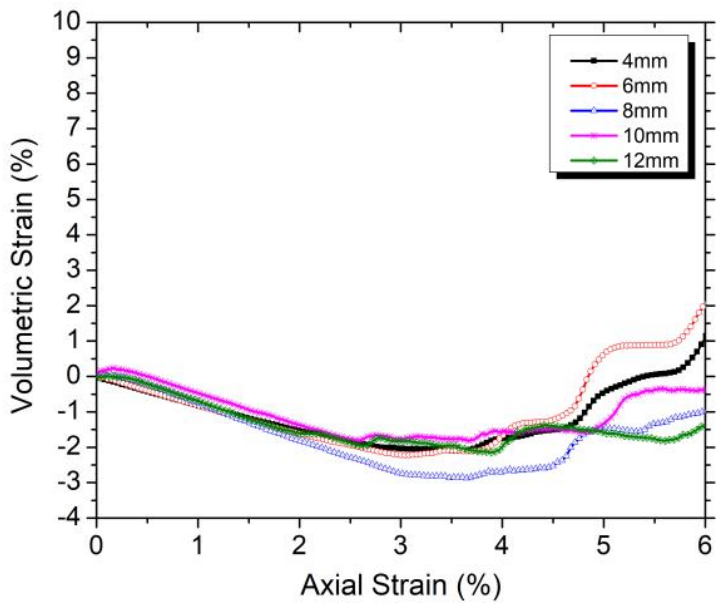

(ii) Volumetric strain.

(a) Case II: Uniform particle size.

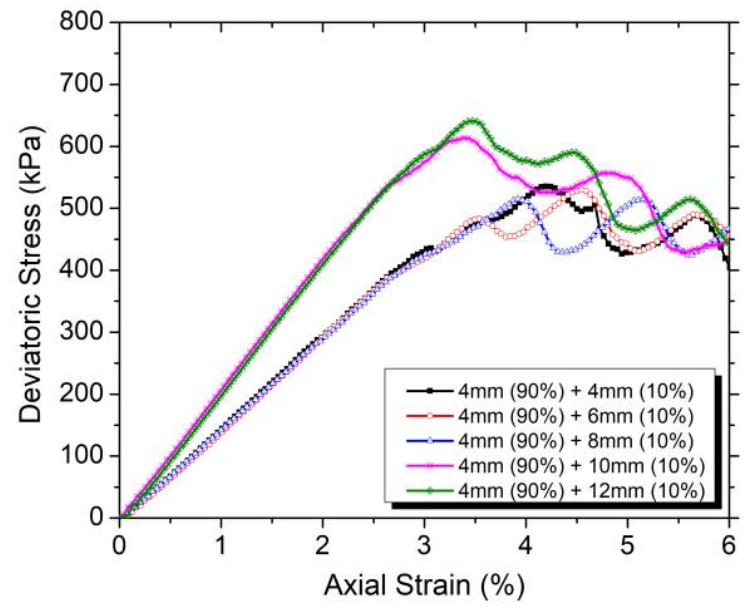

(i) Stress-strain curves.

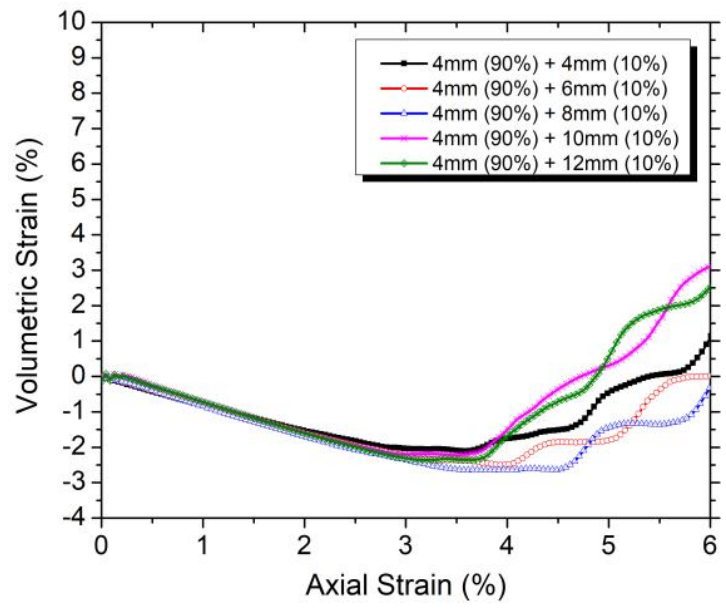

(ii) Volumetric strain.

(b) Case III: $90 \%$ volume with $4 \mathrm{~mm}$ particle base.

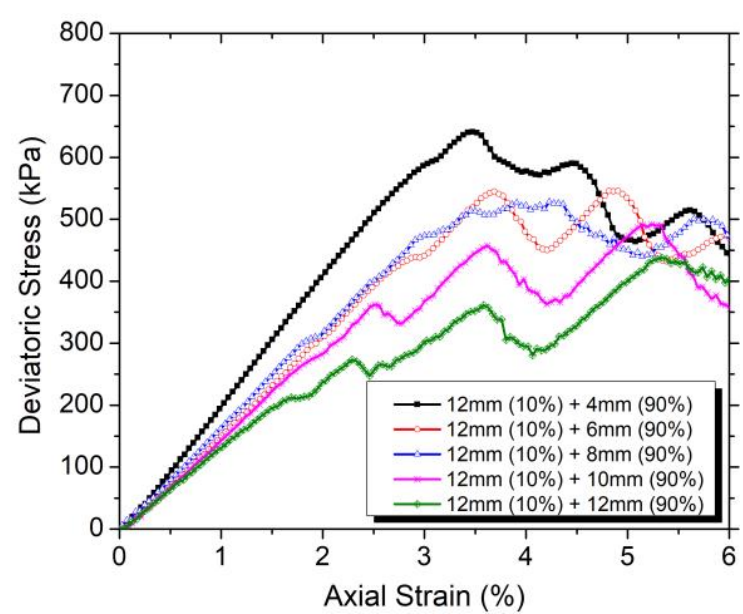

(i) Stress-strain curves.

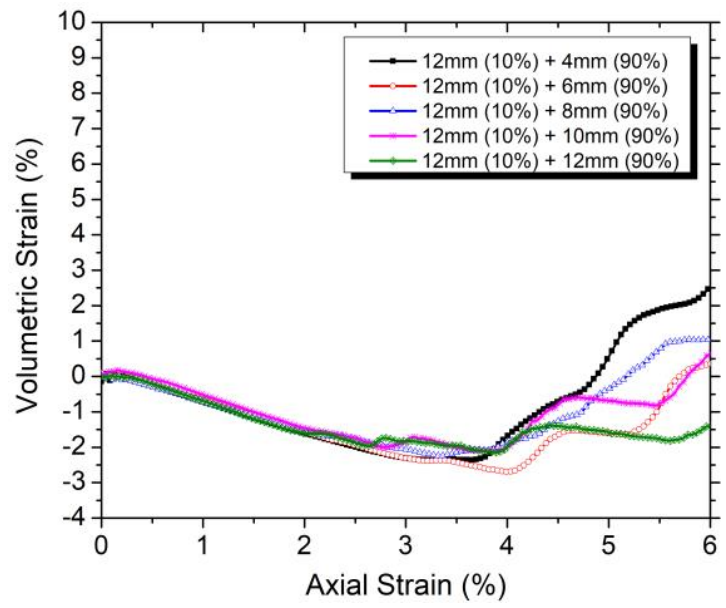

(ii) Volumetric strain.

(c) Case IV: 10\% volume with $12 \mathrm{~mm}$ particle base.

Fig. 8. Stress-strain relation and volume change. 


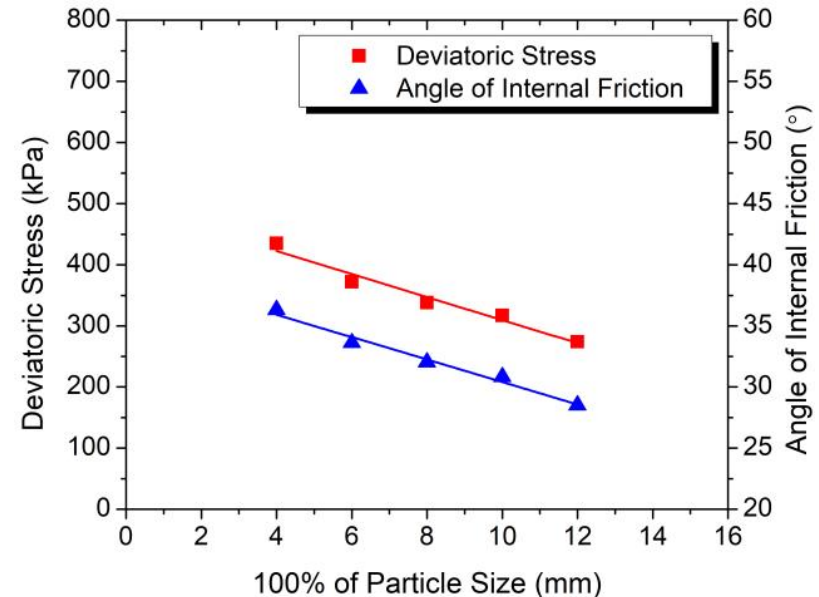

(i) Deviatoric stress and friction angle as a funtion of partical size.

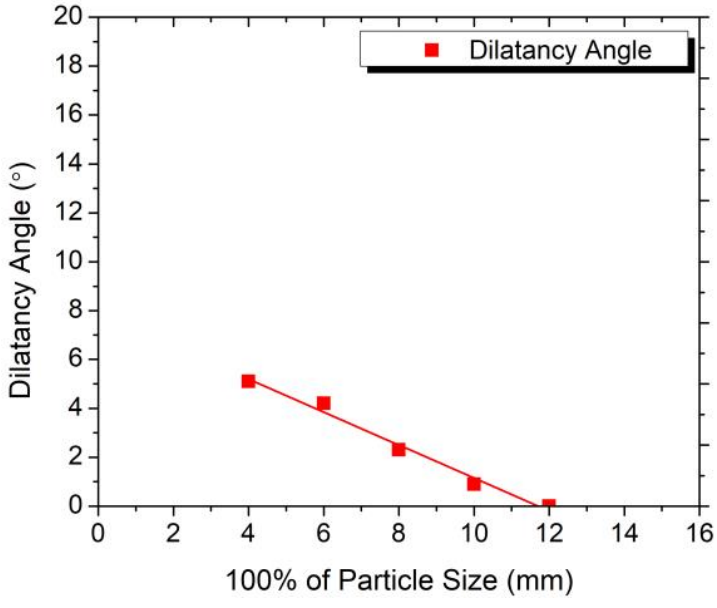

(ii) Dilatancy angle as a funtion of partical size.

(a) Case II: Uniform particle size.

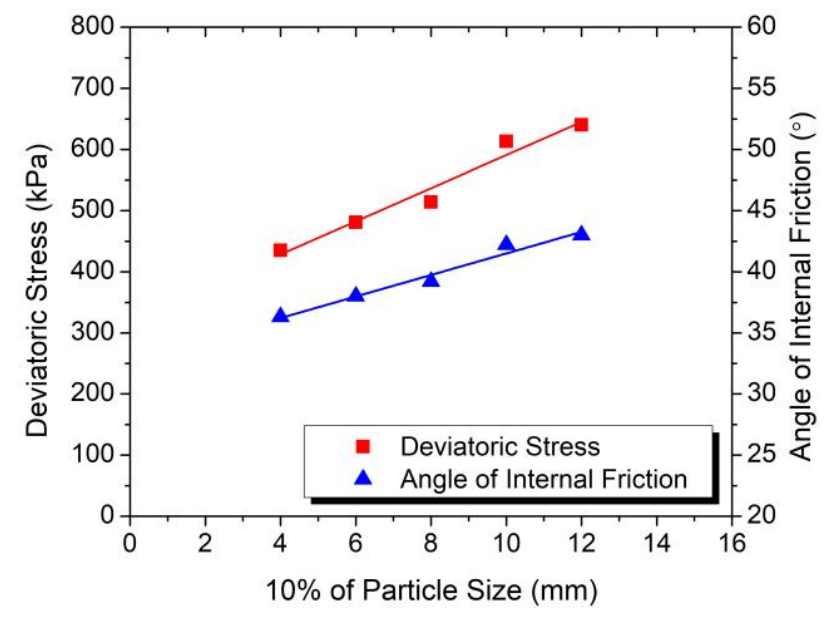

(i) Deviatoric stress and friction angle as a funtion of larger particle size portion.

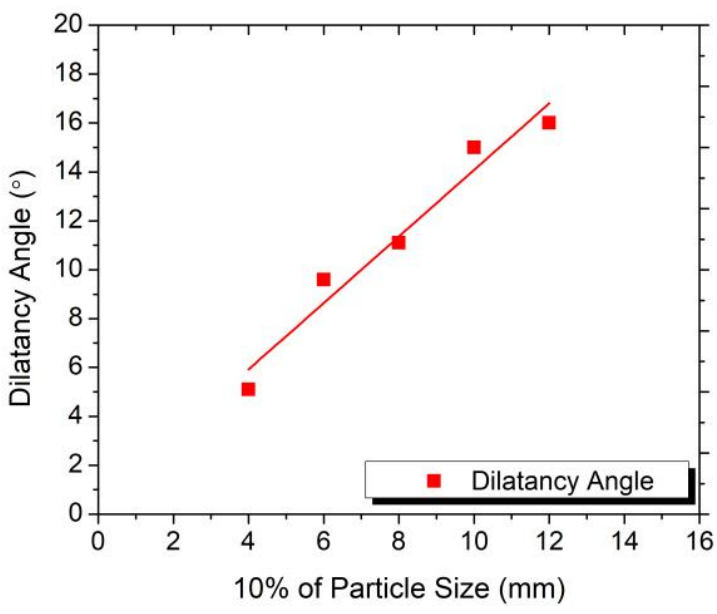

(ii) Dilatancy angle as a funtion of larger particle size portion.

(b) Case III: $90 \%$ of 4 mm-particle base mixed with the remaining $10 \%$ volume consisting of different size particles. 


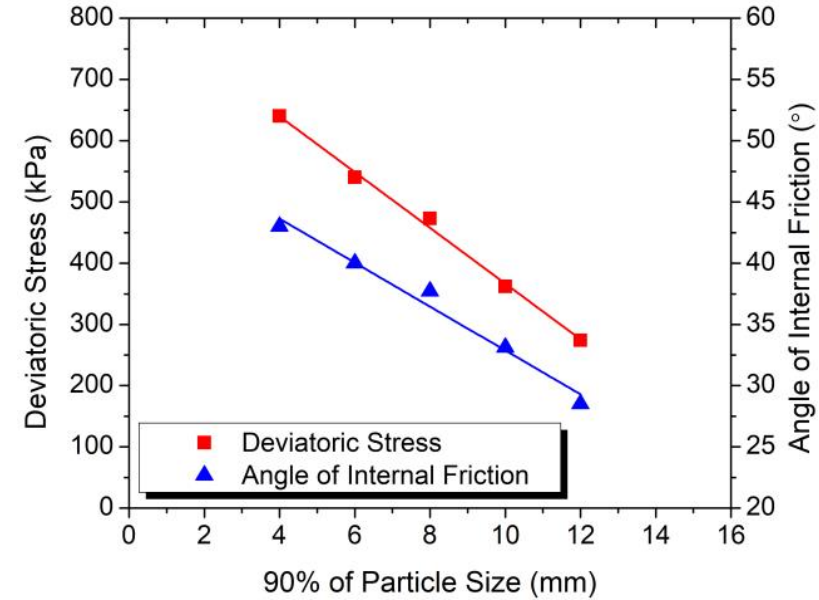

(i) Deviatoric stress and friction angle as a funtion of smaller particle size portion.

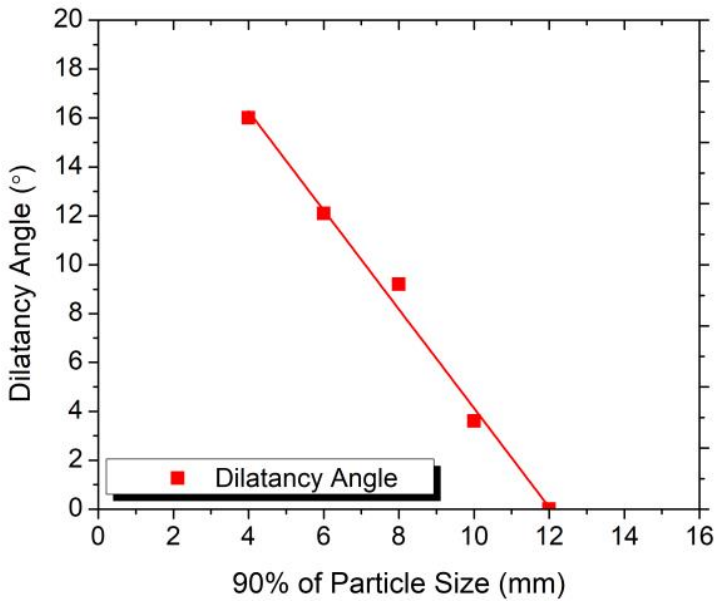

(ii) Dilatancy angle as a funtion of smaller particle size portion.

(c) Case IV: $10 \%$ of $12-\mathrm{mm}$ particles base mixed with $90 \%$ of different size particles.

Fig. 9. Relationship between deviatoric stress, angle of internal friction, and dilatancy angle with particle size.

Among the four cases with different soil gradations, two cases revealed an increase in deviatoric stress, friction angle, and dilatancy angle with a decreasing $D_{50}$. This is because of the increase in the number of particles and particle contacts within Case II specimen's uniform soil as well as a better particle size distribution when increasing the range of the particle sizes with the presence of larger-diameter particles for Case IV. These conditions make soil stronger and more resilient to shear. Conversely, for the other two cases, where the three parameters increase with an increasing $D_{50}$, these cases involve a smaller range of particle sizes with a poorer grain size distribution, which makes the soil weaker. The finding of linear relationship in the deviatoric stresses, friction angle, and dilatancy angle based on particle size is significant since it can help predict soil strength and strain properties when the particle size changes.

\subsection{Observations on shear bands}

In a laboratory triaxial test, it is difficult to observe the weakest plane in a specimen during shear failure or "shear band." The developed DEM model for the triaxial test with a flexible membrane is able to track the shear band during failure. As the granular specimen transmits external forces, internal force chains continuously break and reform (Wilson and Sáez, 2017); thus, the weakest internal forces during shear failure can be traced. A shear band can be tracked by either tracing particle movements or tracing the internal forces in the discrete granular medium. Shear band is more visible and more band-like for the higher confining stress $\sigma_{3}$ of $150 \mathrm{KPa}$ than for the lower $\sigma_{3}$.

To observe and compare the development of the shear bands for different particle sizes and confining pressures, triaxial tests on two specimens with a uniform particle size of $4 \mathrm{~mm}$ and $8 \mathrm{~mm}$ were simulated at three confining pressures. Both specimens generated almost slant band-like shear zones. Figure 10 shows the specimen with 4-mm particles possessing a comparatively thinner shear band area, and the specimen with $8-\mathrm{mm}$ particles possessing a thicker shear band area. The thicker shear band for larger particles may come from the interaction of larger particles when the specimen has a larger area of the specimen involved in the shear band. The movement of the particles on the shear surface also seems larger for large particles as shown by the differences between Fig, 10c and 10f. 


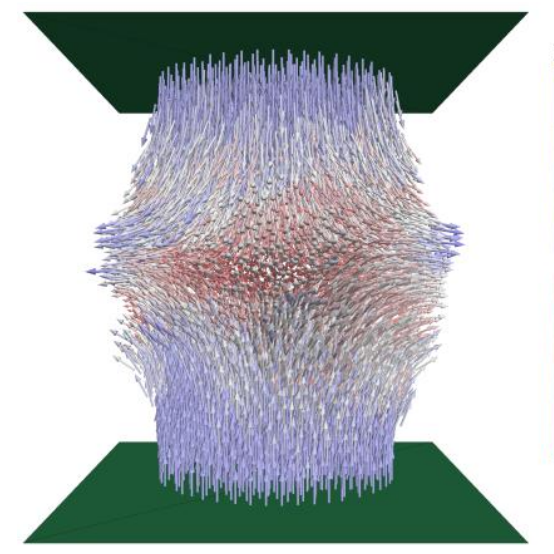

Ball Arrow displaceme

$1.7000 \mathrm{E}-02$

1.6000E-02

$1.4000 \mathrm{E}-02$

.3000E-02

$1.2000 \mathrm{E}-02$
$1.1000 \mathrm{E}-02$

$1.1000 \mathrm{E}-02$
$1.0000 \mathrm{E}-02$

$1.0000 \mathrm{E}-02$
$9.0000 \mathrm{E}-03$

8.0000E-03

$7.0000 \mathrm{E}-03$

$6.0000 \mathrm{E}-03$
$5.0000 \mathrm{E}-03$

$4.0000 \mathrm{E}-03$

$3.0000 \mathrm{E}-03$

.0000E-03

$.0000 \mathrm{E}-03$

$0.0000 \mathrm{E}+00$

(a) Specimen with $4 \mathrm{~mm}$ particles, $\sigma_{3}=35 \mathrm{kPa}$
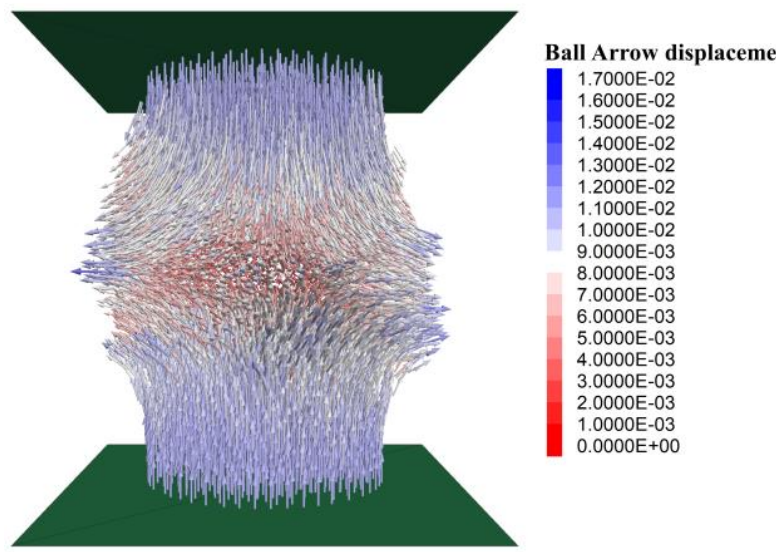

(b) Specimen with $4 \mathrm{~mm}$ particles, $\sigma_{3}=70 \mathrm{kPa}$
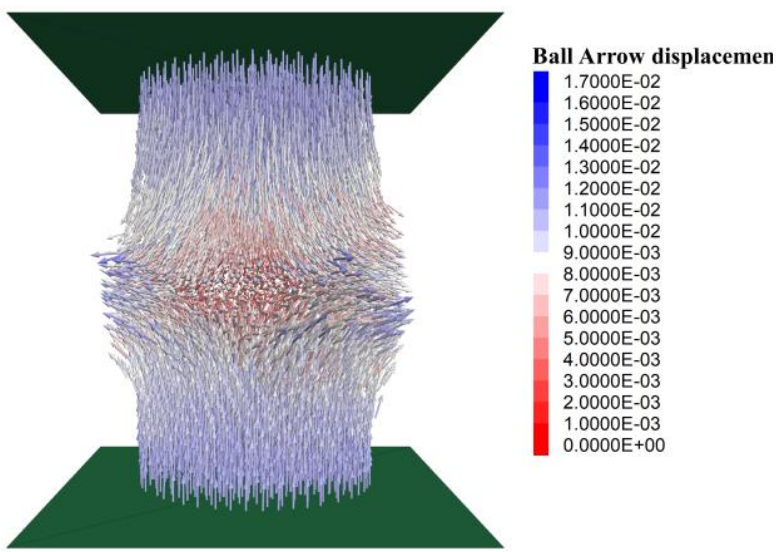

(c) Specimen with $4 \mathrm{~mm}$ particles, $\sigma_{3}=150 \mathrm{kPa}$

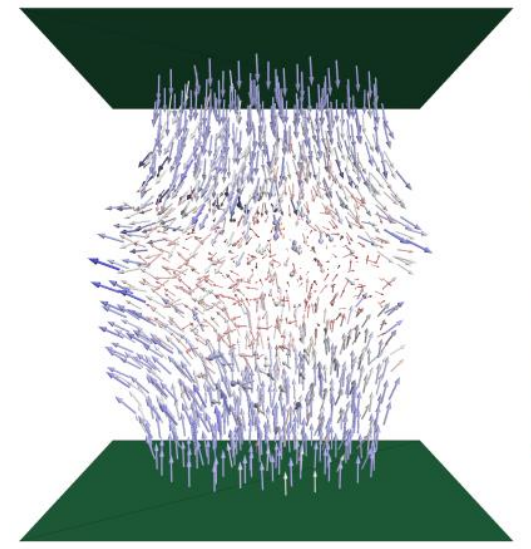

Ball Arrow displaceme

$1.7000 \mathrm{E}-02$

$1.6000 \mathrm{E}-02$
$1.5000 \mathrm{E}-02$

$1.5000 \mathrm{E}-02$

$1.4000 \mathrm{E}-02$
$1.3000 \mathrm{E}-02$

2000E-02

(1000 -02

1.000

$8.0000 \mathrm{E}-03$

$8.0000 \mathrm{E}-03$
$\mathrm{C}-0000 \mathrm{E}-03$

6.0000E-03

$5.0000 \mathrm{E}-03$

$4.0000 \mathrm{E}-03$

$3.0000 \mathrm{E}-03$

$2.0000 \mathrm{E}-03$

$1.0000 \mathrm{E}-03$

$0.0000 \mathrm{E}+00$

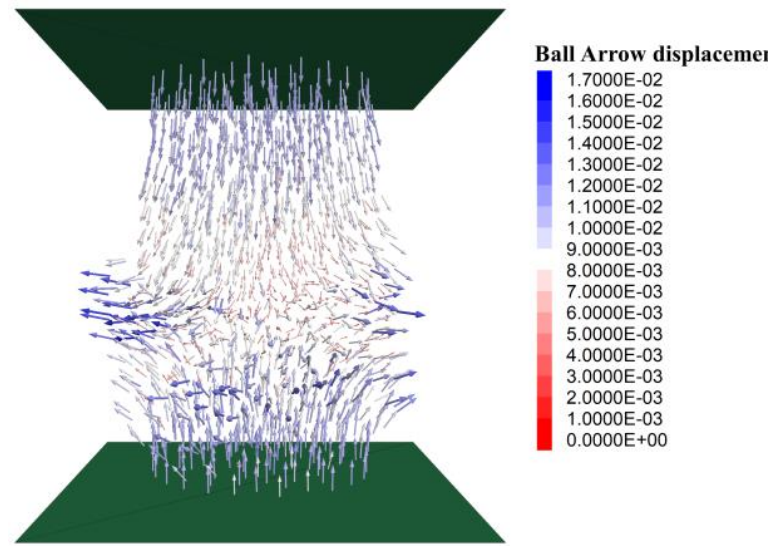

(e) Specimen with $8 \mathrm{~mm}$ particles, $\sigma_{3}=70 \mathrm{kPa}$

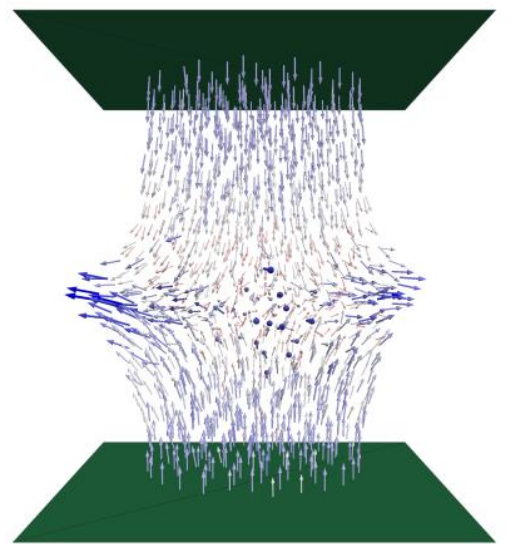

Ball Arrow displacemen $1.7000 \mathrm{E}-02$ $1.6000 \mathrm{E}-02$ 5000E-02 . $4000 \mathrm{E}-02$ $3000 \mathrm{E}-02$ 2000E-02 1000E-02 O. $8.0000 \mathrm{E}-03$ $7.0000 \mathrm{E}-03$ $6.0000 \mathrm{E}-03$ .0000E-03 $.0000 \mathrm{E}-03$ .0000E-03 .0000E-03 $1.0000 \mathrm{E}-03$

(f) Specimen with $8 \mathrm{~mm}$ particles, $\sigma_{3}=150 \mathrm{kPa}$

Figure 10. Shear bands during failure.

The 3D DEM model enables predictions of behavioral characteristics in granular soil. For future study, Geosynthetics will be added to the specimen to study the stress-strain behaviors of reinforced soil in a mechanically stabilized earth (MSE) retaining wall or a geosynthetic reinforced soil (GRS) mass, which will have important applications that can improve the design of these structures. 


\section{Conclusions}

A 3D DEM model was developed using PFC, utilizing a bonded-ball flexible membrane approach to study the strength and strain properties of cohesionless soils as a discontinuous discrete material. Sensitivity analyses were carried out for the microparameters as inputs for the 3D model, which led to the finding that an increase in particle normal stiffness and shear stiffness increases the material elastic modulus. The change of normal and shear stiffness, however, does not affect the peak strength of the soils. Besides, increasing friction coefficient causes an increase in peak strength, but does not affect either the material elastic modulus or the residual stresses of the stress-strain curves. A series of triaxial tests with flexible membranes were simulated to obtain the stress-strain behaviors of granular soil specimens. Four different cases were studied to investigate the effects of particle size and gradation on soil strength and strain properties. Increasing the maximum particle size for soil with gradation gives rise to the strength, the internal friction angle, and the angle of dilatancy, meaning these three parameters increase when increasing the mean particle size $D_{50}$. However, these three factors do not always increase when the mean particle size $D_{50}$ increases but depend instead on the gradations. The relationships between particle size and deviatoric stress, internal friction angle, and dilatancy angle were found to be linear. These linear relationships can provide predictions on soil strength and strain properties when particle sizes change. The developed model with a bonded-ball flexible membrane that allows the study of soil as a discrete material also allows the observance of shear band formation during shear testing.

The developed model and the findings from this research create the foundation for the future research on DEM modeling of reinforced soil in MSE wall and GRS mass. The effects of particle size distribution on the behaviors of a GRS composite with varied spacing and type of reinforcement are to be investigated to provide optimum designs for GRS walls and bridge abutments.

\section{References}

[1] Cundall, P. A., and Strack, O. D. L.: A discrete numerical model for granular assemblies. Geotechnique. 29(1), 47-65 (1979)

[2] Kishino, Y.: Disc model analysis of granular media. Micromechanics of granular materials. Stud. Appl.Mech. 20, 143-152 (1988)

[3] O'Connor, R.: A Distributed Discrete Element Modeling Environment Algorithms, Implementation and Applications. Ph.D. Thesis. Massachusetts Institute of Technology (1996)

[4] Cundall, P.A. and Hart, R.D.: Numerical modeling of discontinua. In: Hudson J.A., (ed.) Comprehensive Rock Engineering. vol. 2, pp. 231-243. Pergamon Press, Oxford (1993)

[5] Addenbrooke, T., Potts, D., and Puzrin, A.: The influence of pre-failure soil stiffness on the numerical analysis of tunnel construction. Geotechnique. 47(3), 693-712 (1997)

[6] Sitharam, T.G., Dinesh, S.V. and Shimizu, N.: Micromechanical modelling of monotonic drained and undrained shear behavior of granular media using three-dimensional DEM. Int. J. Numer. Anal. Methods Geomech. 26(12), 1167-1189 (2002)

[7] Belheine, N., Plassiard, J.P., Donzé, F.V., Darve, F. and Seridi, A.: Numerical simulation of drained triaxial test using 3D discrete element modeling. Comput. and Geotech. 36(1), 320-331 (2009)

[8] Frost, J.D., and Evans, T.M.: Membrane effects in biaxial compression tests. J. Geotech. Geoenviron. Eng. 135(7), 986-991 (2009)

[9] Newland, P., and Allely, B.: Volume changes during undrained triaxial tests on saturated 
dilatant granular materials. Geotechnique. 9(4), 174-182 (1959)

[10] Henkel, D., and Gilbert, G.: The effect measured of the rubber membrane on the triaxial compression strength of clay samples. Geotechnique. 3(1), 20-29 (1952)

[11] Kuhn, M.: A flexible boundary for three-dimensional dem particle assemblies. Eng. Comput. 12(2), 175-183 (1995)

[12] Vermeer, P.A.: The orientation of shear bands in biaxial tests. Géotechnique. 40(2), 223236 (1990)

[13] Powrie, W., Ni, Q., Harkness, R. M. and Zhang, X.: Numerical modelling of plane strain tests on sands using a particulate approach. Géotechnique. 55(4), 297-306 (2005)

[14] Wang, J. and Yan, H.: On the role of particle breakage in the shear failure behavior of granular soils by DEM. Int. J. Numer. Anal. Meth. Geomech. 37(8), 832-854 (2013)

[15] Kozicki, J., Tejchman, J.: DEM investigations of two-dimensional granular vortex- and anti-vortex-structures during plane strain compression. Granul. Matter. 2(20), 1-28 (2016)

[16] Pham, Q.T.: Investigating Composite Behavior of Geosynthetic Reinforced Soil Mass, PhD Thesis, University of Colorado, 358 pages (2009)

[17] Bardet, J.P. and Proubet, J.: A numerical investigation of the structure of persistent shear bands in granular media. Géotechnique. 41(4), 599-613 (1991)

[18] Cil, M. B. and Alshibli, K.A.: 3D analysis of kinematic behavior of granular materials in triaxial testing using DEM with flexible membrane boundary. Acta Geotech. 9(2), 287-298 (2014)

[19] Khoubani, A. and Evans, T.M.: An efficient flexible membrane boundary condition for DEM simulation of axisymmetric element tests. Int. J. Numer. Anal. Methods Geomech. 42(4), 694-715 (2018)

[20] Bolton, M.D.: The strength and dilatancy of sands. Geotechnique. 36 (1), 65-78 (1986).

[21] Rowe, P.W.: The stress-dilatancy relation for static equilibrium of an assembly of particles in contact. Proc. R. Soc. London A, 269, 500-527 (1962)

[22] Seo, M.W., Ha, I.S. and Kim, B.J.: Effects of particle size and test equipment on shear behavior of coarse materials. J. Kor. Soc. Civil Eng. 27(6C), 393-400 (2007)

[23] Kim, D., Sagong, M. and Lee, Y.: Effects of fine aggregate content on the mechanical properties of the compacted decomposed granitic soils. Constr. Build. Mater. 19(3), 189196 (2005)

[24] Ben-David, O., Rubinstein, S.M. and Fineberg, J.: Slip-stick and the evolution of frictional strength. Nature. 463(7277), 76-79 (2010)

[25] Kirkpatric, W.M.: Effects of grain size and grading on the shearing behavior of granular materials. Proc. 6th Int. Conf. Soil. Mech. and Foundation Engineering, Canada. 1, 273277 (1965)

[26] Marschi, N.D., Chan, C.K. and Seed, H.B.: Evaluation of properties of rockfill materials. J. Soil Mech. Found. Div. 98(1), 95-114 (1972)

[27] Xiaofeng, X.U., Houzhen, W.E.I., Qingshan, M., Changfu, W.E.I. and Yonghe, L.I.: DEM simulation on effect of coarse gravel content to direct shear strength and deformation characteristics of coarse-grained soil. J. Eng. Geol. 21(2), 311-316 (2013)

[28] Kim, D. and Ha, S.: Effects of particle size on the shear behavior of coarse-grained soils reinforced with geogrid. Materials. 7, 963-979 (2014)

[29] Sitharam, G.T. and Nimbkar, S. M.: Micromechanical modelling of granular materials: effect of particle size and gradation. Geotech. Geol. Eng. 18, 91-117 (2000)

[30] Bagherzadeh-Khalkhali, A., Mirghasemi, A.A.: Numerical and experimental direct shear tests for coarse-grained soils. Particuology. 7, 83-91 (2009)

[31] Mishra, D., Mahmud, S.N.: Effect of particle size and shape characteristics on ballast shear strength, a numerical study using the direct shear test. In: Proceeding of the 2017 Joint Rail Conference, Philadelphia, USA (2017) 
[32] Islam, M.N., Siddika, A., Hossain, M.B., Rahman, A., Asad, M.A.: Effect of particle size on the shear strength behavior of sands. Aust. Geomech. J. 46(3), 75-85 (2011)

[33] Gupta, A.K.: Effect of particle size and confining pressure on breakage and strength parameters of rockfill materials. Electron. J. Geotech. Eng. 14(H), 1-12 (2009)

[34] Qu, T., Feng, Y.T., Wang, Y. and Wang, M.: Discrete element modelling of flexible membrane boundaries for triaxial tests. Comput. Geotech. 115, 103154 (2019)

[35] Zhao, X. and Evans, T.M.: Discrete simulations of laboratory loading conditions. Int. J. of Geomech. 9(4), 169-178 (2009)

[36] Li, B., Zhang, F. and Gutierrez, M.: A numerical examination of the hollow cylindrical torsional shear test using DEM. Acta Geotech. 10(4), 449-467 (2015)

[37] Wang, Y. and Tonon, F.: Modeling triaxial test on intact rock using discrete element method with membrane boundary. J. Eng. Mech. 135(9), 1029-1037 (2009)

[38] Cheung, G. and O'Sullivan, C.: Effective simulation of flexible lateral boundaries in twoand three-dimensional DEM simulations. Particuology. 6(6), 483-500 (2008)

[39] Binesh, S.M., Eslami-Feizabad, E. and Rahmani, R.: Discrete Element Modeling of Drained Triaxial Test: Flexible and Rigid Lateral Boundaries. Int. J. Civ. Eng. 16(10), 1463-1474 (2018)

[40] Iwashita, K. and Oda, M.: Rolling resistance at contacts in simulation of shear band development by DEM. J. of Eng. Mech. 124(3), 285-292 (1998)

[41] De Bono, J., Mcdowell, G. and Wanatowski, D.: Discrete element modelling of a flexible membrane for triaxial testing of granular material at high pressures. Géotech. Lett. 2(4), 199-203 (2012)

[42] De Bono, J.P. and McDowell, G.R.: DEM of triaxial tests on crushable sand. Granul. Matter. 16(4), 551-562 (2014)

[43] Lu, Y., Li, X. and Wang, Y.: Application of a flexible membrane to DEM modelling of axisymmetric triaxial compression tests on sands. Eur. J. Environ. Civ. Eng. 22(sup1), s19s36 (2018)

[44] Saussus, D.R. and Frost, J.D.: Simulating the membrane contact patterns of triaxial sand specimens. Int. J. Numer. Anal. Methods Geomech. 24(12), 931-946 (2000)

[45] Potyondy, D.O. and Cundall, P.A.: A bonded-particle model for rock. Int. J. Rock Mech. Min. Sci. 41(8), 1329-1364 (2004)

[46] Griffiths, D.V. and Mustoe, G.G.W.: Modelling of elastic continua using a grillage of structural elements based on discrete element concepts. Int. J. Numer. Methods Eng. 50(7), 1759-1775 (2001)

[47] Itasca. Particle flow code in three dimensions. Minneapolis: Itasca Consulting Group (2014)

[48] Ostoja-Starzewski, M.: Lattice models in micromechanics. Appl. Mech. Rev. 55(1), 35-60 (2002)

[49] Coetzee, C.J. and Els, D.N.J.: Calibration of discrete element parameters and the modelling of silo discharge and bucket filling. Comput. Electron. Agric. 65(2), 198-212 (2009)

[50] Lommen, S., Schott, D. and Lodewijks, G.: DEM speedup: Stiffness effects on behavior of bulk material. Particuology. 12, 107-112 (2014)

[51] Ahlinhan, M., Houehanou, E., Koube, M., Doko, V., Alaye, Q., Sungura, N. and Adjovi, E.: Experiments and 3D DEM of triaxial compression tests under special consideration of particle stiffness. Geomaterials. 8, 39-62 (2018)

[52] Marigo, M. and Stitt, E.H.: Discrete Element Method (DEM) for Industrial Applications: Comments on Calibration and Validation for the Modelling of Cylindrical Pellets. KONA Powder and Part. J. 32, 236-252 (2015)

[53] Coetzee, C.J.: Calibration of the Discrete Element Method and the Effect of Particle Shape. Powder Technol. 297, 50-70 (2016) 
[54] Coetzee, C.J.: Review: Calibration of the Discrete Element Method. Powder Technol. 310, 104-142 (2017)

[55] Lin, H. and Zhang, J.: Triaxial tests and DEM simulation on artificial bonded granular materials, Jpn. Geotech. Soc. Spec. Publ. 2(17), pp.660-663 (2016)

[56] Dai, B.B., Yang, J. and Zhou, C.Y.: Observed effects of interparticle friction and particle size on shear behavior of granular materials. Int. J. Geomech, 16(1), 040150111 (2016)

[57] Harehdasht, S.A., Karray, M., Hussien, M.N. and Chekired, M. Influence of particle size and gradation on the stress-dilatancy behavior of granular materials during drained triaxial compression. Int. J. Geomech. 17(9), 04017077 (2017)

[58] Wilson, J. F. and Sáez, E.: Use of discrete element modeling to study the stress and strain distribution in cyclic torsional shear tests. Acta Geotech. 12(3), 511-526 (2017) 